\title{
Link or sink: a modelling interpretation of the open Baltic biogeochemistry
}

\author{
M. Vichi ${ }^{1}$, P. Ruardij ${ }^{2}$, and J. W. Baretta ${ }^{3}$ \\ ${ }^{1}$ National Institute of Geophysics and Volcanology, Bologna, Italy \\ ${ }^{2}$ Royal Netherlands Institute of Sea Research, Texel, The Netherlands \\ ${ }^{3}$ Noctiluca, Wassenaar, The Netherlands
}

Received: 30 June 2004 - Published in Biogeosciences Discussions: 5 August 2004

Revised: 13 September 2004 - Accepted: 29 October 2004 - Published: 4 November 2004

\begin{abstract}
A 1-D model system, consisting of the 1-D version of the Princeton Ocean Model (POM) coupled with the European Regional Seas Ecosystem Model (ERSEM) has been applied to a sub-basin of the Baltic Proper, the Bornholm basin. The model has been forced with $3 \mathrm{~h}$ meteorological data for the period 1979-1990, producing a 12-year hindcast validated with datasets from the Baltic Environmental Database for the same period. The model results demonstrate the model to hindcast the time-evolution of the physical structure very well, confirming the view of the open Baltic water column as a three layer system of surface, intermediate and bottom waters. Comparative analyses of modelled hydrochemical components with respect to the independent data have shown that the long-term system behaviour of the model is within the observed ranges. Also primary production processes, deduced from oxygen (over)saturation are hindcast correctly over the entire period and the annual net primary production is within the observed range. The largest mismatch with observations is found in simulating the biogeochemistry of the Baltic intermediate waters. Modifications in the structure of the model (addition of fast-sinking detritus and polysaccharide dynamics) have shown that the nutrient dynamics are linked to the quality and dimensions of the organic matter produced in the euphotic zone, highlighting the importance of the residence time of the organic matter within the microbial foodweb in the intermediate waters. Experiments with different scenarios of riverine nutrient loads, assessed in the limits of a 1-D setup, have shown that the external input of organic matter makes the open Baltic model more heterotrophic. The characteristics of the inputs also drive the dynamics of nitrogen in the bottom layers leading either to nitrate accumulation (when the external sources are inorganic), or to coupled nitrification-denitrification (under strong organic inputs). The model indicates the perma-
\end{abstract}

\author{
Correspondence to: $\mathrm{M}$. Vichi \\ (vichi@bo.ingv.it)
}

nent stratification to be the main feature of the system as regulator of carbon and nutrient budgets. The model predicts that most of the carbon produced in the euphotic zone is also consumed in the water column and this enhances the importance of heterotrophic benthic processes as final closure of carbon and nutrient cycles in the open Baltic.

\section{Introduction}

The estimate of net ecosystem production (NEP) of coastal shelf systems is relevant for the understanding of carbon dynamics in the world ocean (Smith and Hollibaugh, 1993). Many efforts have been recently undertaken to analyse the role of the continental shelves to act as carbon sources and/or sinks (Gattuso et al., 1998; Tsunogai et al., 1999; Gazeau et al., 2004), and the fragmentary picture obtained so far is complicated by some discordances in the results. Focusing on a well-studied shelf sea such as the Baltic Sea (Fig. 1), recent estimates report a large variability in the total NEP, from largely positive values in the Gulf of Gdansk to negative values in estuaries, with a slightly positive regional average of about $0.2-0.5 \mathrm{mmol} \mathrm{C} \mathrm{m}^{-2} \mathrm{~d}^{-1}$ (Thomas et al., 2003a,b; Gazeau et al., 2004). The assessment of carbon budgets and its use for predicting the response to climate changes is, however, hampered by various uncertainties. The coastal zone is characterised by tight linkages between pelagic and benthic processes and the response of these two systems to physical and biological perturbations are substantially different. Moreover, the functioning of marine ecosystems is not solely related to the carbon dynamics, but this component is loosely linked to the biogeochemical cycles of the other main macronutrients. These cycles are ultimately modulated by hydrodynamics and by the different food-web interactions that can develop in the highly-variable coastal zones.

To further understand and predict the behaviour of these systems, it is necessary to assess the response to both phys- 


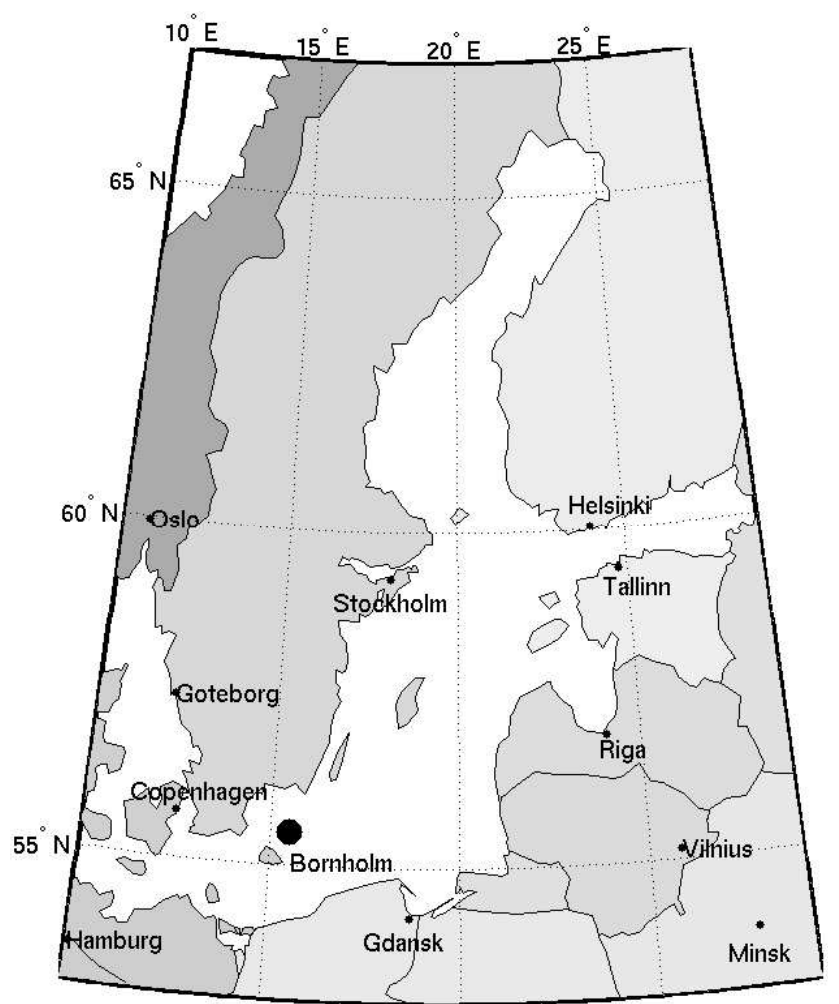

Fig. 1. Map of the Baltic Sea and location of the one-dimensional model.

ical and biological perturbations. In theory, this can be achieved by measuring the biogeochemical fluxes under different conditions, but in practice it is impossible to measure all relevant in situ biological rates at a sufficiently high sampling frequency and spatial distribution. Therefore, limited process-oriented experiments supported by coupled physical-biogeochemical models are important tools to test the significance of the many dynamical connections and to identify the key processes and the possible cause-effect relationships among variables.

The first requirement for this task is to have a mathematical description of marine biogeochemical processes that has been proved to have a certain degree of predictability under different conditions. This part is discussed in this paper with a one-dimensional (1-D) representation of a southern Baltic Proper water column located in the Bornholm basin. The model was used as a tool to explain the evolution of the available biogeochemical variables, highlighting skills and limitations of current parameterisations of marine biogeochemistry. The reference dataset for the Baltic Proper was the Baltic Environmental Database (Wulff and Rahm, 1990, BED) accessed via the SwingStations web-interface (Sokolov and Wulff, 1999). The original aim of this coupled model application to the open Baltic was thus to establish whether a long-term (decadal) hindcast, using highfrequency $(3 \mathrm{~h})$ meteorological data for the surface-forcing would be able to reproduce the independent BED-data set of hydrochemical data. In other words: can a 1-D description of an essentially 3-D system capture some, most or even all of the biogeochemical dynamics of the system? The short answer is: thanks to the specific vertical structure of the open Baltic and its weak and variable large-scale circulation, yes it can. The long answer, including detailed supporting evidence is provided in this paper.

Indeed, the main hydrographic feature of the Baltic Proper is the permanent salinity stratification, which is maintained by intermittent inflows of salt water from the North Sea into the Arkona and Bornholm basins, and by the runoff of the major drainage rivers. The two major effective inflows in last 25 years occurred in 1975-1976 and in 1993, delimiting a long stagnation period without a renewal of the waters in the deeper parts of the basin. A subset of this time window (1979-1990) is the target period of this investigation. The Baltic Proper can be ideally schematised as a three layer system of surface, intermediate and bottom waters (BSW, BIW and BBW, respectively), and this study further confirms this view. The permanent pycnocline is located at about $50-60 \mathrm{~m}$ depth acting as a stable barrier to the vertical transport of dissolved nutrients. In general, deep-water mixing has a seasonal variability with higher rates in fall and winter (Stigebrandt, 1987) and is dominated by the energy input from the wind via inertial currents, internal waves and, in waters shallower than $150 \mathrm{~m}$, also by the coastal boundary layer (Axell, 1998). During summer, a thermocline is formed in the upper layer at around $20 \mathrm{~m}$. This physically identifies the intermediate layer, which is generally isohaline but acts as a further nutricline (Rahm et al., 2000).

After establishing that vertical water-column dynamics in the Baltic effectively dominate over advective processes (which cannot be explicitly represented in 1-D models), a second aim has been to attempt quantifying both the ecological role of the benthic system in oxic, hypoxic and anoxic conditions and the effect of winter deep-mixing events on the redistribution of nutrients over the watercolumn, accounting dynamically for the time-varying density structure of the water column. Last but not least, our aim has been to provide a set of scenarios of external nutrient loads (both from freshwater and atmospheric sources) and to investigate the response of the system, specifically focusing on the fate of carbon. Obviously, this is fraught with uncertainties in a 1-D system, as freshwater runoff is a purely advective process.

\section{Methods}

The ecosystem model used in this work is a coupling between a reviewed version of the European Regional Sea Ecosystem Model (Baretta et al., 1995, ERSEM) and the 1-D version of the Princeton Ocean Model (Blumberg and Mellor, 1987, POM). The 1-D version of POM is essentially a vertically resolved boundary layer model, which is based on the 


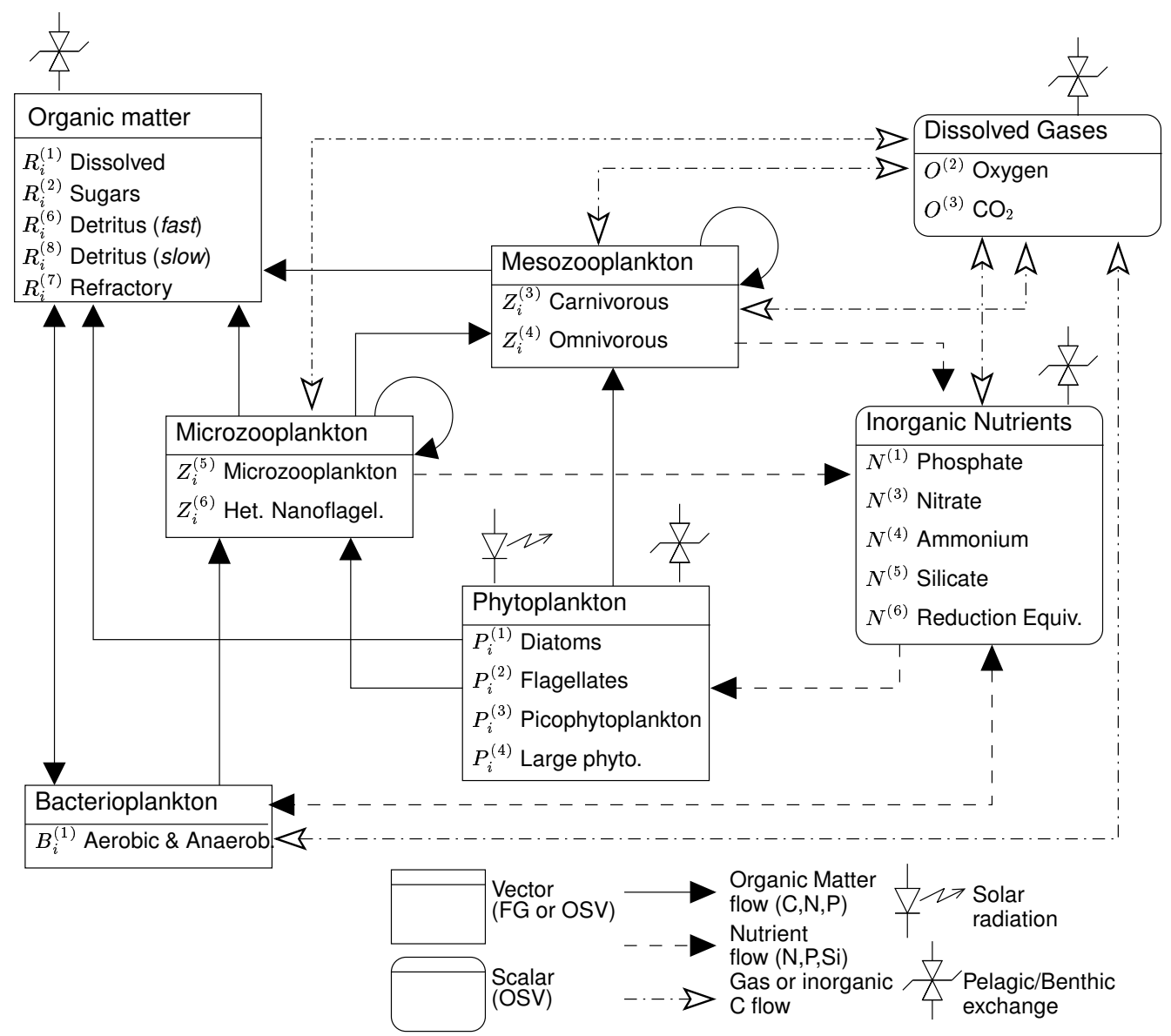

Fig. 2. Scheme of the pelagic interactions of the ERSEM III model. Each functional group is mathematically treated as a vector whose components are the content of $\mathrm{C}, \mathrm{N}, \mathrm{P}$, and $\mathrm{Si}$ (only for diatoms), e.g. $P_{i} \equiv\left(P_{c}, P_{n}, P_{p}, P_{s}\right)$. FG = functional group with C, N, P components; $\mathrm{OSV}=$ ordinary state variable, scalar component either in units of one of the elements or in other units (e.g. oxygen, in $\mathrm{mmol}_{2} \mathrm{~m}^{-3}$ ).

turbulence closure scheme proposed by Mellor and Yamada (1982, M-Y, version 2.5). The model determines the dynamical vertical structure and the actual turbulent diffusive vertical transport in the water column, as driven by the boundary conditions at the air-sea interface and at the bottom.

The biomass-based model ERSEM, by construction, simulates the matter flows between the lower trophic levels of marine food webs and their role in the biogeochemical cycles of the major elements, C, N, P, Si and O. The pelagic food web (Fig. 2) is composed of a basic set of functional groups. The biomass of a functional group is determined by the amount of $\mathrm{C}, \mathrm{N}, \mathrm{P}$ (and $\mathrm{Si}$ for diatoms) contained in the cells, and the different elements are exchanged differentially with the inorganic pools and with the other groups. ERSEM is thus potentially capable to describe conditions of unbalanced phytoplankton growth and, thanks to the inclusion of an explicit microbial compartment, the dynamical shifting between various food webs (for instance, from the microbial loop to the classical grazing food web). The benthic system (Fig. 3) describes both the trophic web interactions in the benthos (Ebenhöh et al., 1995; Blackford, 1997) and nutrient regeneration processes occurring in the first $0.3 \mathrm{~m}$ of sediments (Ruardij and Van Raaphorst, 1995). The sediments are divided in three dynamical layers in order to simulate the processes occurring under oxic, anoxic and denitrifying conditions. Several groups of benthic organisms affect the distribution of organic matter in the sediments and determine the locations where the remineralisation effectively occurs. ERSEM was recently reviewed by Vichi (2002), and the full set of equations was unified with a common mathematical formulation. The revised version (ERSEM III) has the same scientific background of ERSEM I/II (Baretta et al., 1995; Baretta-Bekker et al., 1997), with the addition of some innovations and bug-fixes.

In particular, specifically to deal with the open Baltic features, the model was improved with the treatment of hypoxic conditions and coupled denitrification. In general, the biogeochemical cycle of inorganic $\mathrm{N}$ in coastal seas is subject to a complex array of regulatory mechanisms involving the two main species $\mathrm{NO}_{3}^{-}$and $\mathrm{NH}_{4}^{+}$and the microbially mediated 


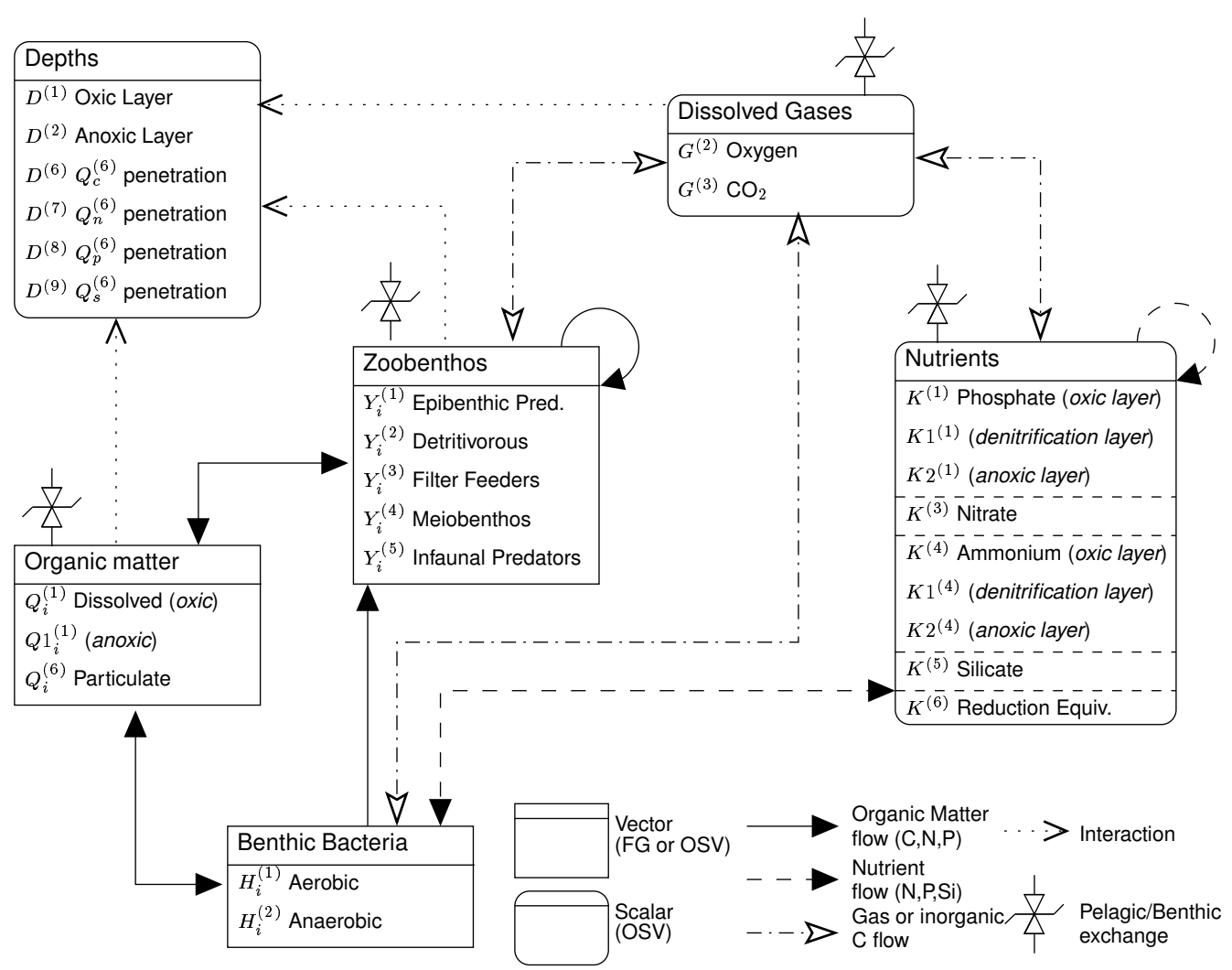

Fig. 3. Scheme of the benthic interactions of the ERSEM III model (cf. caption in Fig. 2).

processes of ammonification (remineralisation), nitrification, denitrification and nitrogen fixation (Herbert, 1999). Such processes (excluding fixation) mainly take place in the sediments, therefore the simulation of benthic dynamics is of great importance. The dominance of one process over another is largely determined by the redox conditions in the water column, which are, in turn, connected to the hydrodynamics and to the rate of detritus deposition and mineralisation. The standard ERSEM formulation already comprised the parameterisation of these processes in the sediment model (Ruardij and Van Raaphorst, 1995), mainly described as first order reactions. In ERSEM III, the parameterisation of denitrification has been modified to include this process as a nitrogen sink in the Baltic (Wulff and Stigebrandt, 1989; Eilola and Stigebrandt, 1999). The denitrification sites are first and foremost the sediments (Tuominen et al., 1998; Herbert, 1999) but denitrification has been demonstrated to occur also in the Baltic water column (Rönner and Sörensson, 1985). In order to incorporate the dependence on the organic matter availability, denitrification has been coupled to the biological oxygen demand under hypoxic/anoxic conditions (anoxic mineralisation), both in the water and in the sediments.

Since the Baltic Proper has shown an alternation of positive and negative redox conditions during the investigated stagnation period, it is important that the model is able to deal with both situations, in order to shift from nitrification to denitrification. In the denitrification reaction, nitrate is used as an electron acceptor for metabolic activity at low oxygen concentrations and the model formulation has been set up such that pelagic bacteria switch to nitrate consumption, modifying the redox conditions. When oxygen is completely depleted, hydrogen sulphide is formed at the watersediment interface, as a result of the bacterial reduction of sulphate ions in the sediments. The bacterial oxygen demand is thus redirected to the sulphate ions, and the formation of one sulphide ion corresponds to the consumption of two oxygen molecules. The concept of "negative oxygen" (Fonselius, 1981) is based on this reaction, and multiplication by 2 of the $\mathrm{H}_{2} \mathrm{~S}$ value gives the "negative" $\mathrm{O}_{2}$. This process was parameterised by allowing the dynamical coexistence of oxygen and $\mathrm{HS}^{-}$in the sediments and in the water column ("reduction equivalents" $K^{(6)}$ and $N^{(6)}$, respectively, see Figs. 2 and 3), and the molecular diffusion of these reduction equivalents at the water-sediment interface. Therefore, the absolute amount of oxygen (and hence the redox condition of the system) is given by the actual oxygen concentration minus the concentration of reduction equivalents multiplied by the stoichiometric factor 2 . In presence of oxygen, reduction equivalents are again reoxidised to sulphate with a fast first-order reaction. 
(a) Temperature (Surface)
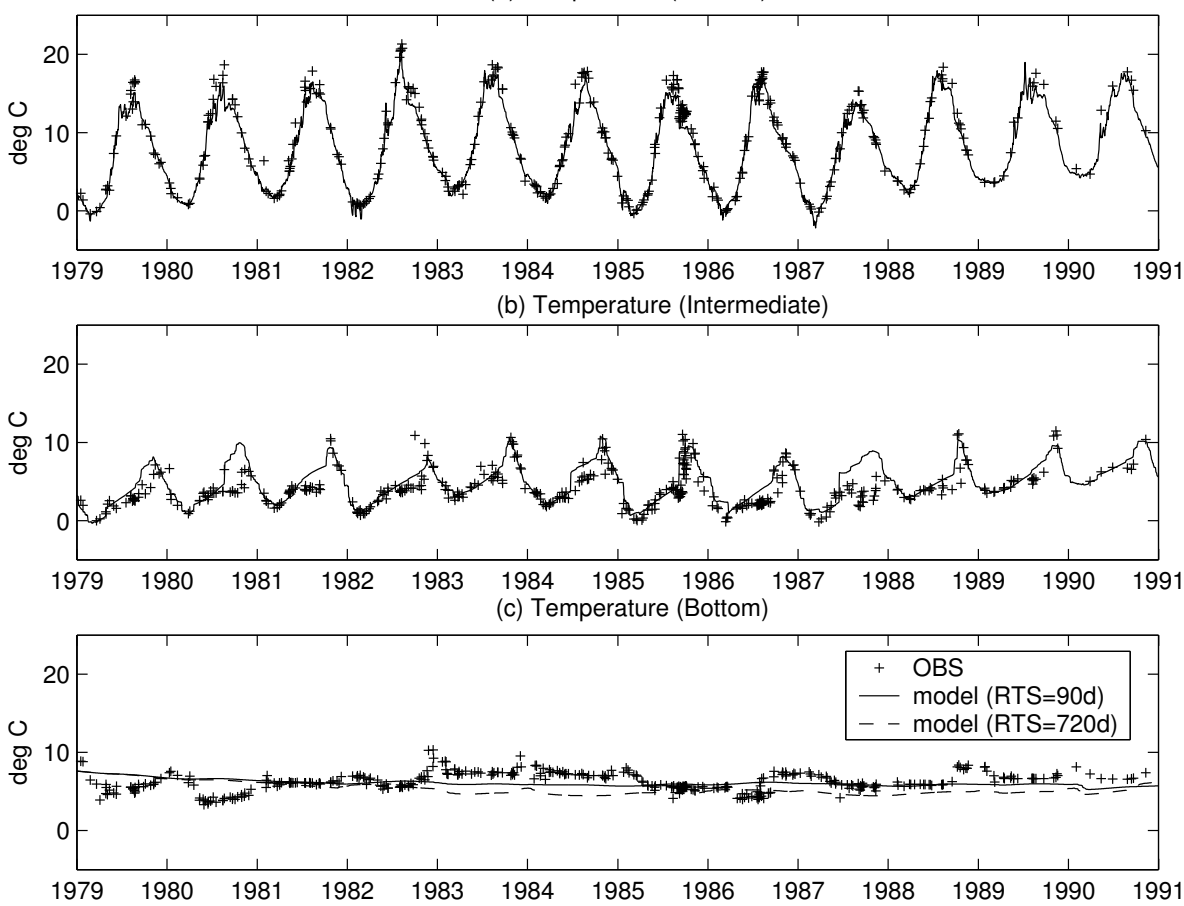

Fig. 4. Observed and simulated temperature evolution at the surface (a), in the intermediate layer ((b), $40 \mathrm{~m}$ depth) and at the bottom (c). Bottom panel also shows the results of a sensitivity experiments with a relaxation time scale (RTS) to the climatological salinity profile of $720 \mathrm{~d}$.

\section{Model implementation}

\subsection{Model location and setup}

The 1-D model is located in the Bornholm basin at $55.5^{\circ} \mathrm{N}$ $15.5^{\circ} \mathrm{E}$, where the mean depth of the water column is $80 \mathrm{~m}$ (Fig. 1). The model has 20 vertical levels with a logarithmic depth distribution both at the surface and at the bottom. The physical model is forced with surface fluxes computed from the 1979-1990 atmospheric data provided by L. Mueller at SMHI to the EU-funded BASYS project (BAltic Sea SYstem Study). The frequency of the meteorological data is three hours except for precipitation (half-daily) and solar radiation (daily). The model interpolates between two three-hourly values to the numerical time step of $540 \mathrm{~s}$ via a linear interpolation and the fluxes are calculated using the prognostic sea surface temperature (SST) by means of the bulk formulations collected by Castellari et al. (1998). In order to resolve the daily cycle, the astronomically-derived solar radiation according to Dobson and Smith (1988), corrected by threehourly cloudiness from the BASYS dataset, has been preferred to the daily average value given in the original dataset. Oxygen transfer rates at the sea surface have been computed by means of the parameterisations proposed by Liss and Merlivat (1986) and Wanninkhof (1992).

The validity of the 1-D physical approximation in the Baltic Proper is confirmed by different model results (Om- stedt and Axell, 1998, see also below) and is mainly linked to the absence of a well-defined general circulation and the weakness of the tidal forcing. The circulation cells are mostly confined to the sub-basin level, with small horizontal exchanges between the basins (Lehmann and Hinrichsen, 2000), therefore enhancing the relevance of the vertical turbulent transport processes driven by the exchange of momentum and heat at the air-sea interface. Nevertheless, a 1-D model has obvious limitations in simulating deep phenomena such as dense water entrainment, the observed seasonal variability of the deep water mixing and the formation of density currents (Axell, 1998; Stigebrandt, 1987). Moreover, the imposition of realistic forcing functions at the surface tends to destroy the permanent salinity gradient that needs to be restored by means of specialised parameterisations. In order to partially include these phenomena, the pycnocline variability has been parameterised as in Stigebrandt (1987) and Omstedt and Axell (1998) by substituting the background eddy-diffusivity of the M-Y with an inverse function of the buoyancy frequency $N$, as $K_{b}=\alpha N^{-1}$. Stigebrandt (1987) found the parameter $\alpha$ to be in the order of $2.0 \times 10^{-7} \mathrm{~m}^{2} \mathrm{~s}^{-2}$. Since this value generally underestimates the energy flux derived from observations in shallower waters (Axell, 1998), $\alpha$ has been increased to $1.5 \times 10^{-6} \mathrm{~m}^{2} \mathrm{~s}^{-2}$ in this work. The long-term maintenance of the water column structure was instead provided by adding a Newtonian damping to a climatological profile of salinity with a relaxation time scale (RTS) 
(a) Intermediate-Surface

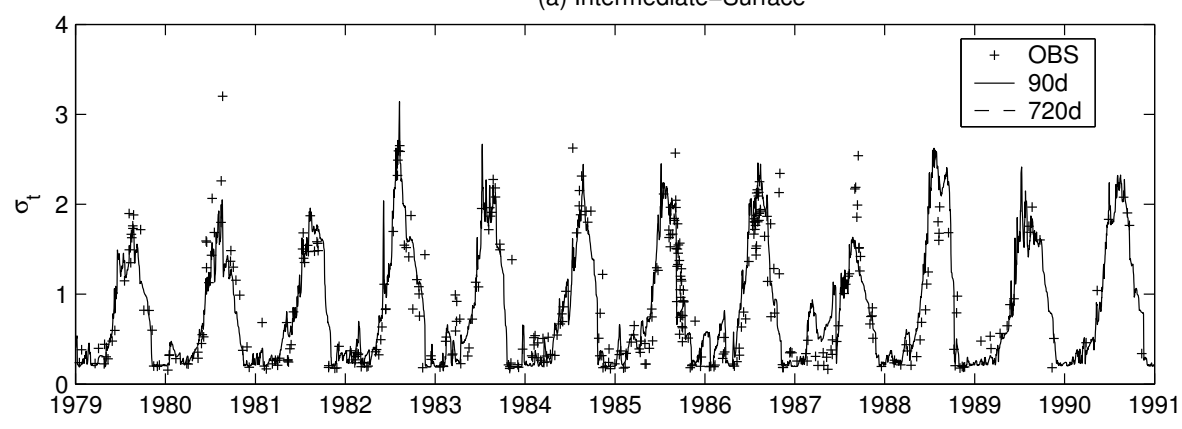

(b) Bottom-Surface

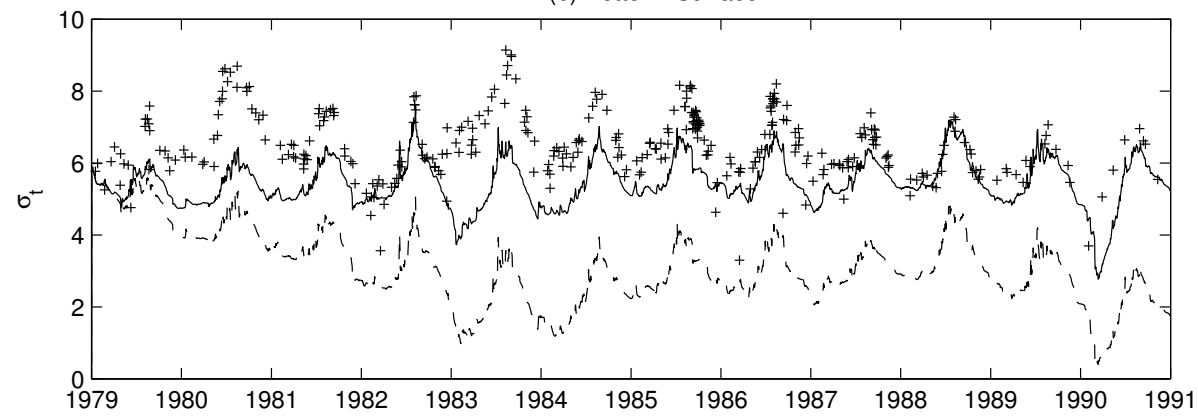

Fig. 5. Observed and simulated density difference between intermediate and surface layers (a), and bottom and surface layers (b). Bottom panel also shows the results of a sensitivity experiments with a relaxation time scale to the climatological salinity profile RTS $=720 \mathrm{~d}$.

of $90 \mathrm{~d}$ (see also Sect. 4.1). Finally, to parameterise the effects of freshwater inputs, surface salinity data from BED were assimilated in the first level of the model with a simple nudging scheme and a time constant of $8 \mathrm{~d}$.

The model was initialised with winter average conditions for temperature salinity, nutrients and oxygen from BED. The pelagic variables were initialised with homogeneous conditions in the vertical.

\subsection{Atmospheric deposition and river loads}

The chemical compounds considered important for the marine environment that can also be deposited by atmospheric processes are mostly nitrogen and phosphorus. The information concerning these inputs in the Baltic sea are annual budgets at basin-level for phosphorus (HELCOM, 1987, 60007000 tons) and monthly wet atmospheric nitrogen deposition with a 1 by 1 degree spatial resolution (L. Grannat, Stockholm University, collected in the framework of the BASYS project). Since the known amount of phosphorus deposition does not have any temporal or spatial distribution, it was decided to neglect this term and only include the nitrogen deposition as an external forcing function. These data are spatially and temporally resolved, and higher frequency deposition information can be deduced from precipitation data in the BASYS database. The monthly wet deposition was divided by the total monthly precipitation and the resulting deposition per unit of precipitation was multiplied by the amount of precipitation every $12 \mathrm{~h}$. Scaling this value to the day, gives an estimate of the deposition flux of nitrate and ammonium (both in mmol $\mathrm{N} \mathrm{m}^{-2} \mathrm{~d}^{-1}$ ) with a $12 \mathrm{~h}$ frequency for the Bornholm area. A background rate was also considered to account for the dry deposition flux. This is a constant fraction that may range from 5 to $20 \%$ of the wet deposition, and was set to $20 \%$.

The inclusion of river loads to the Baltic Proper was done taking a very simplistic approach. The total nutrient loads to the Baltic Proper were estimated from monthly data over the period 1979-1990 (Stålnacke et al., 1998). The available information concerns the input of inorganic $\mathrm{P}$ as phosphate, inorganic $\mathrm{N}$ as nitrate plus nitrite, inorganic $\mathrm{Si}$ as silicate and the total $\mathrm{P}$ and $\mathrm{N}$ loads. The organic $\mathrm{P}$ and $\mathrm{N}$ fractions were estimated as the difference between the total load and the inorganic part. The surface flux was obtained dividing by the total surface of the Baltic Proper (HELCOM, 1987, $211,069 \mathrm{~km}^{2}$ ) and by the number of days in each month. An estimate of the input of organic carbon related to the load of organic $\mathrm{N}$ and $\mathrm{P}$ is necessary to balance the organic matter input. A Redfield ratio with the N-component was assumed, as this gives the higher absolute amount of POC due to the $\mathrm{N}$-enriched characteristic of the organic inflows.

There are several uncertainties connected to the assessment and practical use of nutrient load measurements, and this issue is further discussed in Sect. 7 with a sensitivity analysis on different combinations of the external nutrient 
(a) Oxygen Saturation (Surface)
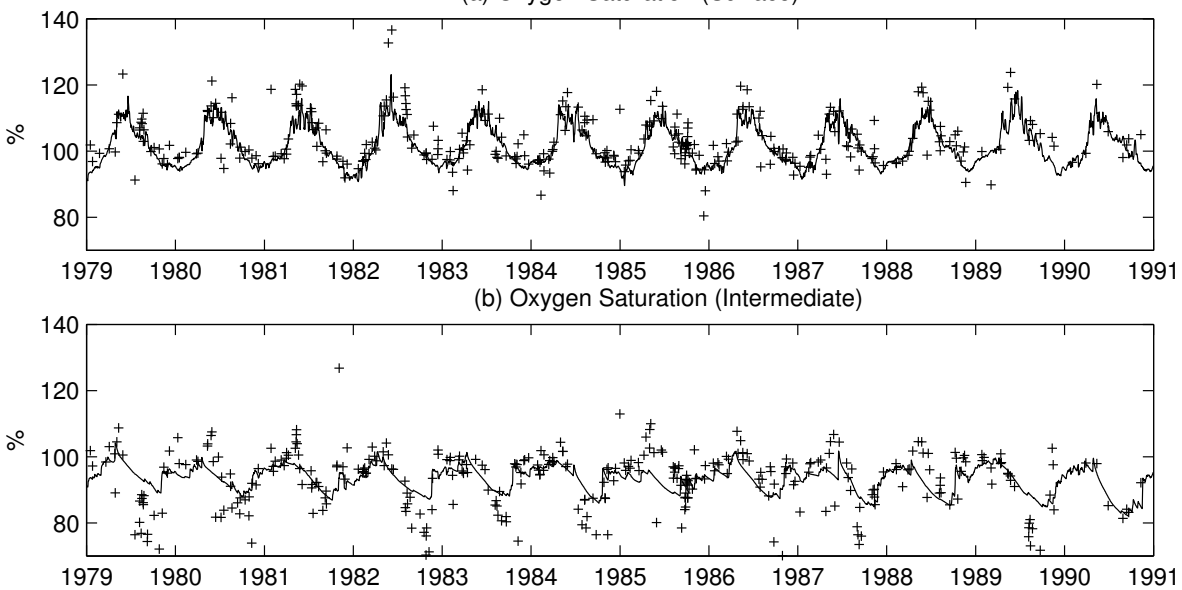

(c) Dissolved Oxygen (Bottom)

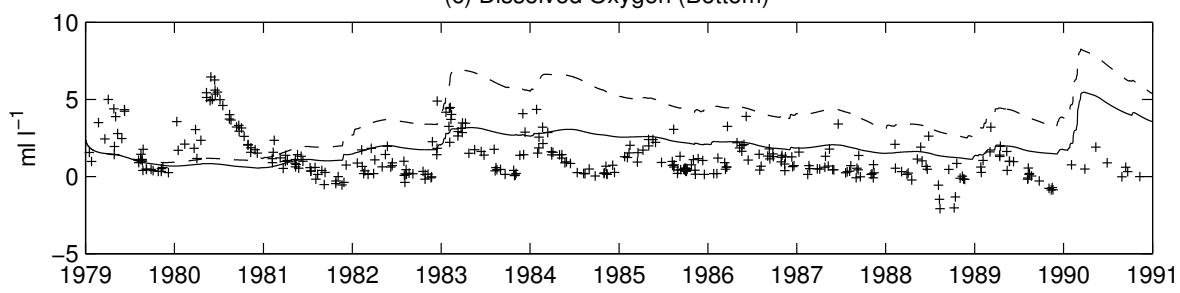

Fig. 6. Observed and simulated oxygen saturation at the surface (a) and in the intermediate layer (b). Panel (c) shows the evolution of the dissolved concentration for the simulation with a relaxation time scale for salinity RTS $=90 \mathrm{~d}$ (continuous line) and RTS $=720 \mathrm{~d}$ (dashed line). Negative values are indicative of the presence of $\mathrm{HS}^{-}$ions.

loads. For the reference experiments shown in the next section it was decided to use a minimal set of the external inputs, consisting of the atmospheric loads and only the organic fraction of the river inputs. It is assumed that, within the limits of the data themselves, these forcings provide a lower bound for the supply of external nutrients to the Bornholm basin.

\section{Simulation results}

\subsection{Water column structure}

Figure 4 shows the model results for temperature compared with the BED data at the surface and in the intermediate and bottom levels. At the surface, the modelled temperature is in near-perfect agreement with the observations. Also the warming trend in the winter minima from the beginning of 1988 is perfectly matched by the model. Such good results indicate that the empirical formulations used to compute the surface fluxes from the meteorological data are appropriate for this basin, and that the time evolution of the SST is completely determined by the exchanges at the surface. Deeper in the water column ( $40 \mathrm{~m}$ depth, Fig. $4 \mathrm{~b}$ ), the model generally overestimates the heating in the BIW. Particularly in 1980-1981 and 1987 the model predicts temperatures higher than the observed ones in spring and summer but the overall annual variability is satisfactorily reproduced, especially in the last years of the simulation. There are periods in which the BBW remains warmer because of the buoyancy flux connected to the presence of denser waters from the Sound, and this feature lasts throughout more energetic mixing periods as in winter 1986-1987. The model failure in reproducing this variability of the bottom temperature evolution can thus be explained by the absence of the horizontal entrainment of deep saltier waters, indirectly highlighting the basin-scale nature of this phenomenon.

The three-layered structure of the Baltic Proper and its annual variation is confirmed in Fig. 5 by means of the density difference between the surface and the intermediate and bottom layers. The seasonal variability of the thermocline is evident and there is a clear separation of the BSW and BIW generally lasting from May to middle October. The model is rather good in reproducing the observed stratification, particularly showing the difference between the less stratified period 1979-1981 and the presence of more stable conditions in 1982-1986. A remark was already made for the year 1987 in the temperature, and this is even more visible here in the density difference. The model is less satisfactory in the simulation of the variability of the permanent pycnocline (Fig. 5b). The initial adjustment to the surface forcings leads to a progressive loss of the vertical structure that is recovered only in the last years. The extent of the winter erosion is well-matched but the spring-summer maxima are underestimated, indicating an underpredicted stratification between the BIW and the BBW. 
(a) Nitrate (Surface)

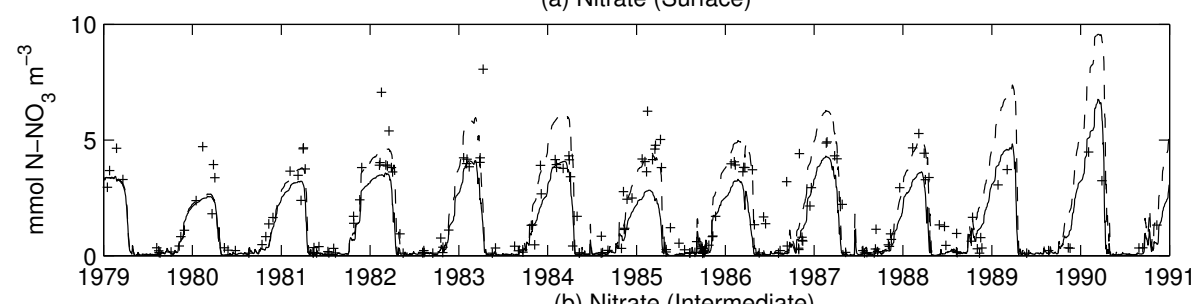

(b) Nitrate (Intermediate)

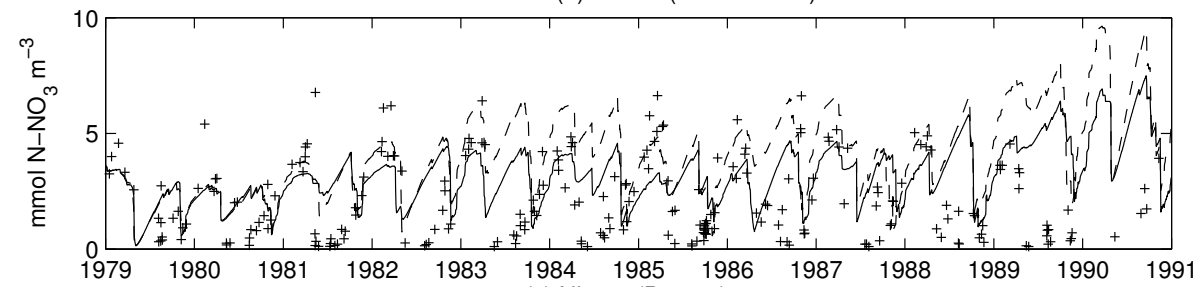

(c) Nitrate (Bottom)

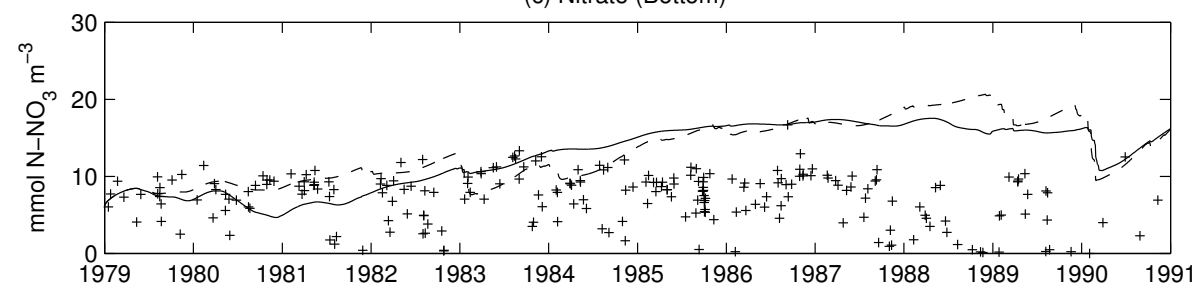

Fig. 7. Observed and simulated nitrate concentration at the surface (a) and in the intermediate (b) and bottom (c) layers. The continuous line is the simulation with the relaxation time scale for salinity RTS $=90 \mathrm{~d}$ and the dashed line has RTS $=720 \mathrm{~d}$.

The years 1983 and 1990 have the highest wind velocities, and the model responds with a deep mixing that is also observed in 1990-1991 but missed in 1983 where the model and the observations diverge. As seen in the temperature as well, this mixing injected warm waters in the BBW that lasted three years because the stability was preserved by the presence of bottom denser waters. This feature highlights the 3-D structure of the BBW, which can only be partly accounted for with the parameterised damping to a climatological salinity profile. In particular, Figs. $4 \mathrm{c}$ and $5 \mathrm{~b}$ show the results of a sensitivity analysis on the value of the relaxation time scale to this climatological profile (RTS, from $90 \mathrm{~d}$ to $720 \mathrm{~d}$ ). While the BSW and BIW are not particularly affected by this parameter, the results in the BBW show that a relatively short time scale is necessary to control the density drift. On the other hand, this strong relaxation partially dampens the winter erosion of the pycnocline and therefore underestimates the winter supply of nutrients to the BSW as shown in the next section.

\subsection{Hydrochemistry}

Due to a lack of long-term measurements of gross primary production and community respiration, the only (indirect) information available to compare the model behaviour with system-level biological activity at the decadal time scale is oxygen saturation. Figure 6 shows that the model is in good accordance with the data over the full 12 years' period, espe- cially in describing the timing of oversaturated conditions at the surface which reflects net community production. Oxygen in the BIW (Fig. 6b) is characterised by a clear seasonal signal with undersaturation troughs reaching values of $70 \%$ or lower and episodes of oversaturation (especially in 1981 and 1985-1988). This seasonal variability is only partially matched by the model, which does capture the variation but with a reduced range of amplitudes. Particularly, the data hint at higher levels of primary production during summer with a sharp late-summer start of the consumption processes that cease with the breaking of the thermocline in October. Deeper in the BBW, the 1-D model has almost no seasonal variability and cannot simulate the ventilation due to horizontal processes such as the 1980 event, although it captures the long-term dampening of the seasonal variation due to the persistence of the stagnation conditions. Clearly, the model does identify that portion of the variance which is driven by vertical processes, as for example in winter 1982-1983 and in 1990 (see also Fig. 5). With a large RTS, the seasonal ventilation is enhanced in these specific years (Fig. 6c), but interestingly, the long-term decrease rate in the bottom oxygen concentration is also higher. This is explained by the simultaneous increase of organic matter supply due to the larger availability of $\mathrm{N}$ in the surface layer as shown in Fig. 7. In fact, with the slow relaxation the organic matter flux is about $10 \%$ larger and the sediment oxygen demand increases by about $25 \%$ on average. 
(a) Phosphate (Surface)
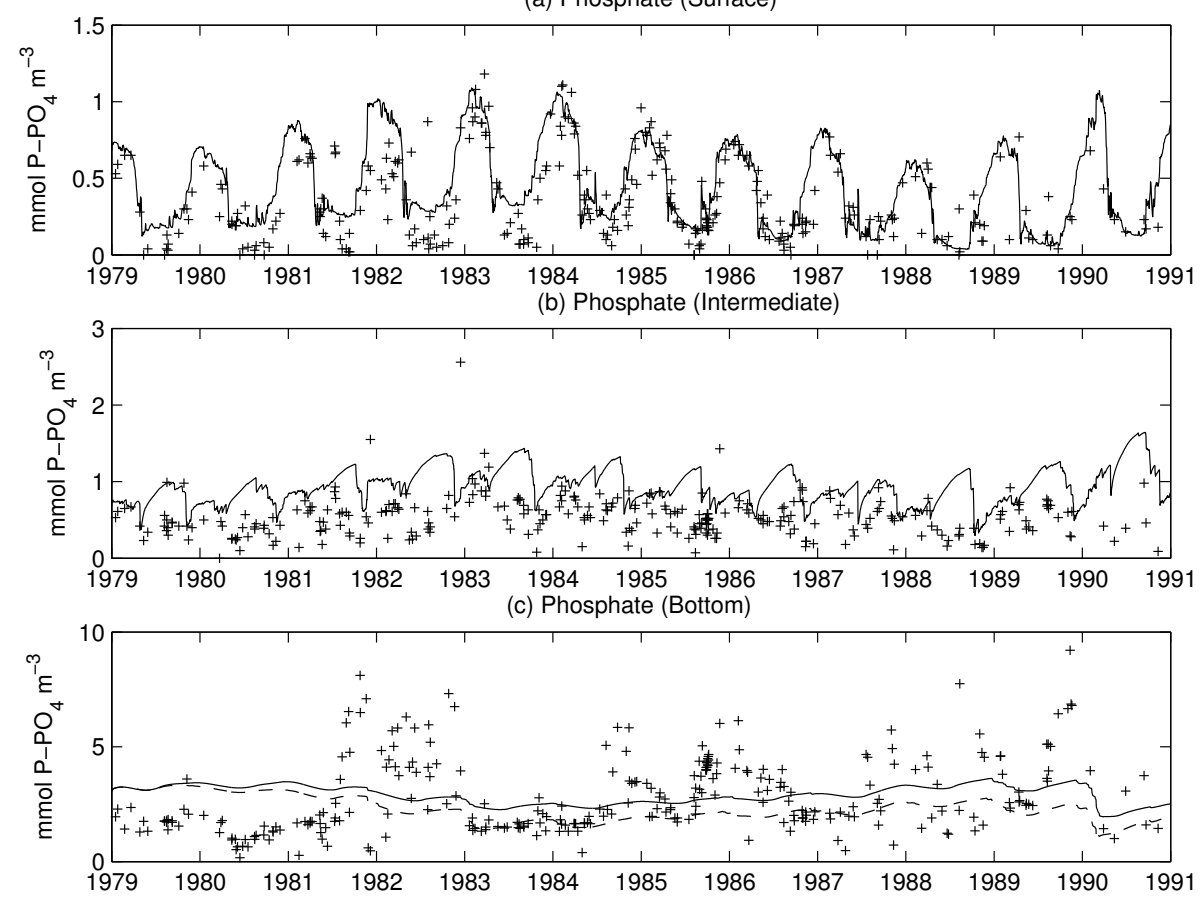

Fig. 8. Observed and simulated phosphate concentration at the surface (a) and in the intermediate (b) and bottom (c) layers. The continuous line is the simulation with RTS=90 d and the dashed line has RTS=720 d (only shown for the bottom layer).

Figure 7 shows the comparison between observations and model results for nitrate. The hindcasting of nitrate time distribution is satisfactory at the surface but fails in the intermediate and bottom layers where the model predicts an overall accumulation of this compound (Fig. 7b,c). The observations suggest that nitrate levels are low in early-summer in the BIW, probably due to a continuation of the production phase (also suggested by the persistence of oxygen saturation, Fig. 6b). In the BIW the model gives a correct winter replenishment but fails in maintaining low summer concentrations. After the spring bloom, the simulated BIW concentration increases because of local remineralisation of ammonium (not shown), and the eventual nitrification leads to an accumulation of (unutilised) nitrate. Inorganic $\mathrm{N}$ accumulates in the BIW until the autumn break-up of the seasonal thermocline. This discrepancy indicates the absence of some important processes in the model formulation and is further discussed in Sect. 5. Nitrate in the BBW has a large variability without an evident seasonal signal. Due to the complex array of N-transformations in the sediments (Herbert, 1999), it is likely that the observations reflect local processes of ammonification and coupled nitrification-denitrification. However the model predicts a clear accumulation which may be linked to the over-predicted oxic conditions with respect to the observations and thus to reduced denitrification. The average denitrification rate in the simulated sediments is 0.14 mmol N m${ }^{-2} \mathrm{~d}^{-1}$ with autumn peaks of 0.2 in the run with RTS $=720 \mathrm{~d}$. Reported values from the Gulf of Finland and the Gulf of Bothnia range from 0 to 0.95 (Tuominen et al., 1998; Stockenberg and Johnstone, 1997) with a clear seasonal pattern connected to both the organic matter supply and the activity of the benthos. Simultaneous masurements of sedimentation (rates and quality) and denitrification rate are therefore necessary, because it is difficult to assess whether the low denitrification predicted by the model is due to a lower supply of organic particles or to incorrect parameter settings.

The model is valuable in explaining the winter replenishment of phosphate as a consequence of the deep mixing (Fig. 8). However, the major feature is the mismatch at the surface during the summer periods. The modelled summer phytoplankton in the BSW has very low $\mathrm{N}: \mathrm{C}$ internal ratios, limiting the biomass production and therefore the uptake of phosphate with consequent accumulation of $\mathrm{PO}_{4}$. Only in the last three years, the progressive increase of $\mathrm{N}$ in the BIW leads to a balancing of the nutrient supply to the surface layers during summertime. The overestimation of P-content is also evident in the BIW (Fig. 8b), where the model behaves similarly as for $\mathrm{N}$-species (Fig. 7b). The simulation predicts a summer increase in contrast with an observed decay, although the seasonal pattern is less clear than in the case of nitrate. Interestingly, the model reasonably explains the background evolution of the bottom concentration especially after 1983. The peak events cannot be simulated by the model and are apparently not correlated to the inflows of dense waters from the Arkona Basin (Sect. 4.1). Nevertheless, the model 
(a) Silicate (Surface)
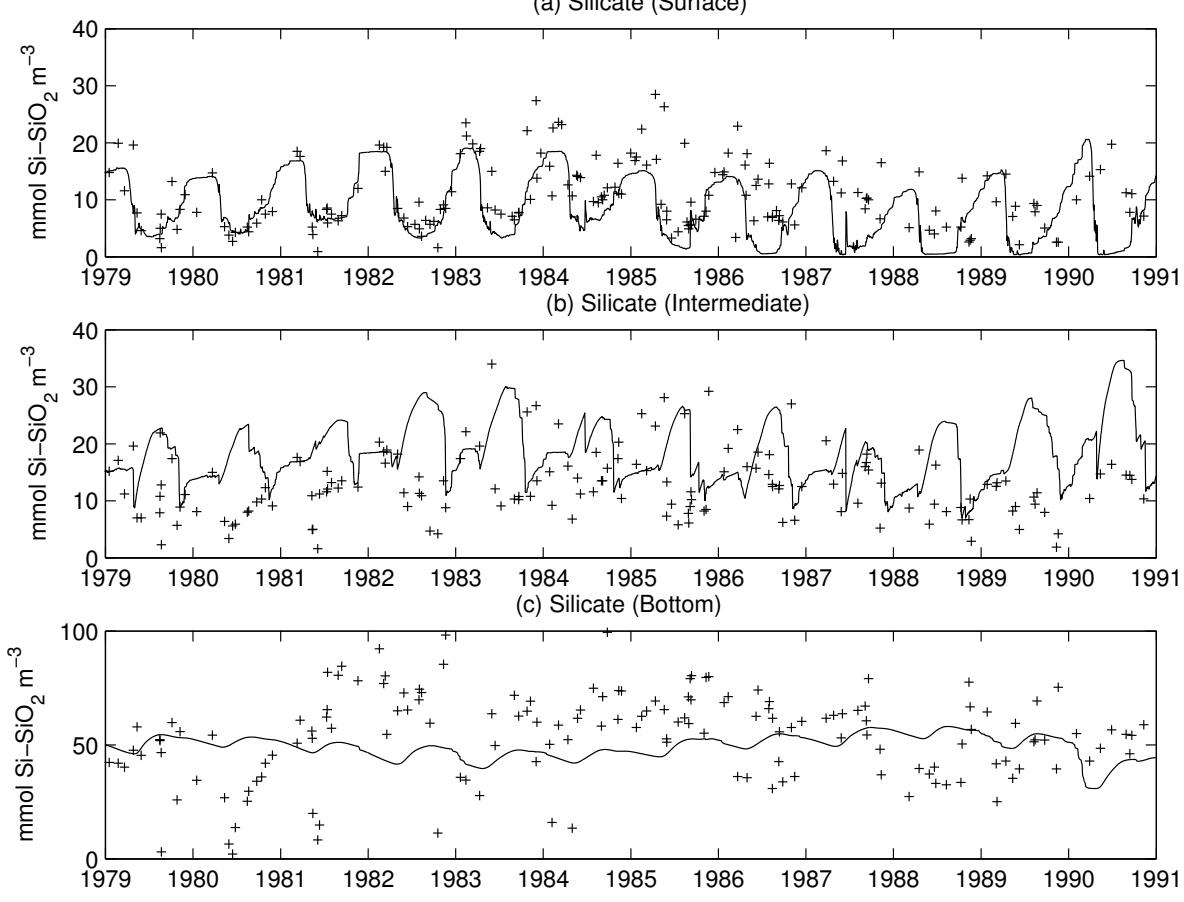

Fig. 9. Observed and simulated silicate concentration at the surface (a) and in the intermediate (b) and bottom (c) layers.

gives indications that the bottom concentration is linked to the oxic conditions, because the ventilation event in 1983 leads to lower $\mathrm{PO}_{4}$ concentration when the deep stratification is less constrained as in the RTS $=720 \mathrm{~d}$ run (Fig. $8 \mathrm{c}$ ).

The dynamics of silicates are shown in Fig. 9. This nutrient is considered to be non-limiting for diatoms in the Baltic Proper, because distinct concentrations remain in the surface layer also during the spring/summer period (HELCOM, 1996). The model, especially in the first 5 years is in good agreement with data but shows a deepening of the spring troughs in the second half of the simulation period. Data in this period are more scattered and it is difficult to assess whether this trend is realistic. In the model, this spring consumption is due to the increased availability of $\mathrm{N}$-compounds that enhance diatom blooms and thus the uptake of silicate. In addition, these results have been obtained after the introduction of a first-order dissolution rate of the biogenic silica in the water $\left(0.1 \mathrm{~d}^{-1}\right)$. This term needs to be further investigated and supported by measurements of the realistic dissolution rates, but, nevertheless, judging from the model, it seems to be a necessary process for a proper simulation of the near-surface silicate dynamics.

\subsection{Chlorophyll and phytoplankton}

As reported in the assessments of the Helsinki Commission (HELCOM, 1990, 1996), the Bornholm basin and the southern Baltic Proper in general, normally shows three phytoplankton peaks in the year, a sharp spring peak, a smaller summer peak and a relatively higher one with a larger time extension in autumn (Hagström et al., 2001). However, as depicted in Fig. 10, the scattering of the Chl-a data makes it difficult to identify a clear succession in the phytoplankton or even the presence of a distinct spring peak. The data suggest that the phytoplankton standing stocks are more abundant in summer than the values simulated by the model. Part of this discrepancy could be explained by the simplified parameterisation used for $\mathrm{Chl}$ in the model, which is a simple linear function of the C-content. A new parameterisation of prognostic Chl synthesis in the cells, based on the work by Geider et al. (1998), has been prepared and could lead to improvements in the simulation of the summer period. It is expected that a more refined parameterisation would lead to a better resolution of phytoplankton vertical distribution. Some preliminary simulations with Geider's formulation have shown that summer dynamics are modified as a consequence of the spring bloom. Particularly, the location of the subsurface Chl maximum is moved more into the BIW, which could also contribute to better match the nutrient observations at that depth.

The only evidence of summer blooms in the models are in 1984 and 1987, the years in which the density difference between the BSW and BIW is reduced either in time (1984) or in amplitude (1987, see Fig. 5). This indicates that the shortterm variability of physical processes can be an important source of nutrients for the BSW that can enhance summer productivity in some specific years. 


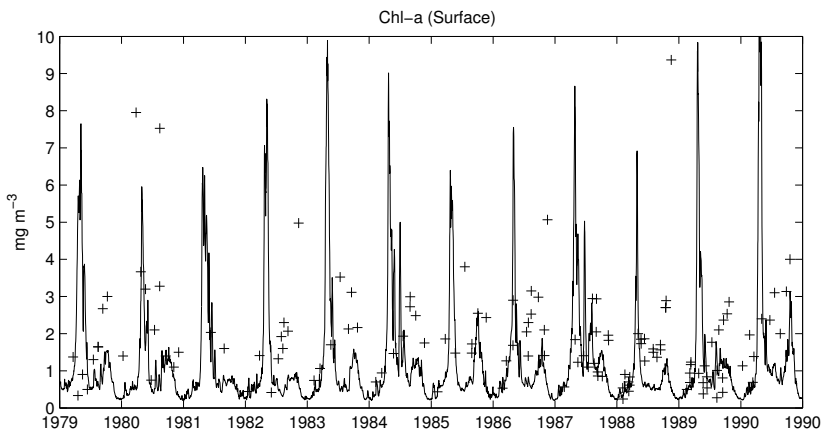

Fig. 10. Observed and simulated chlorophyll- $a$ concentration at the surface (average of the first $20 \mathrm{~m}$ ). Data from the ICES Oceanographic Data Centre, http://www.ices.dk.

The monthly mean values of the phytoplankton succession are shown in Fig. 11. The model predicts a spring bloom mainly composed of diatoms and flagellates in agreement with the observations (HELCOM, 1990; Nommann and Kaasik, 1992). An interesting finding is that the summertime biomass can be maintained only by including a functional group like state variable $P^{(4)}$ (Fig. 2). So far, model results suggest that a sufficient condition for summer dominance of a specific phytoplankton group is a combination of slow growth rates and low predation rates, which is the parameterised functional strategy of group $P^{(4)}$ in the model.

HELCOM (1990) reports that autumn peaks in the Bornholm basin are mainly composed of diatoms, with a small presence of flagellates. The model instead shows a persistence of slow-growing phytoplankton especially in September. When nutrients become available at the thermocline break-up, this group has attained a large standing stock which partially retards the diatom development. A sensitivity experiment performed without this class has shown that autotrophic nanoflagellates takes the role of slow-growing phytoplankton, with a substantial increase during summer. Picophytoplankton is instead not affected by the absence of $P^{(4)}$. However, also in that case, the autumn bloom of diatoms is still not so high as reported, but it is also not visible in $\mathrm{Chl}$ data in Fig. 10.

The role of picophytoplankton should also be investigated in more detail and with the aid of some specific observations. Model results show a strong persistence of this group under almost all seasonal conditions because of the competitive ecological functionalities parameterised in the model (fast growth rates, low light limitation and only one predator, the heterotrophic flagellates). Although some observations give indications of early blooms of the smaller autotrophic plankton (Nommann and Kaasik, 1992), this behavior needs to be further supported by more accurate information.

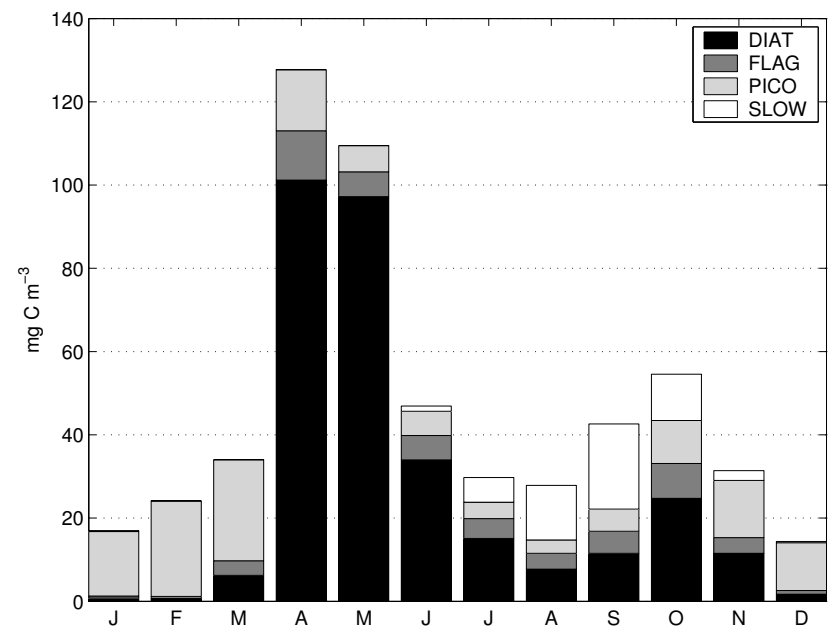

Fig. 11. Phytoplankton succession (average of the first $20 \mathrm{~m}$ ). DIAT $=$ diatoms $P^{(1)} ;$ FLAG = autotrophic nanoflagellates $P^{(2)} ; \mathrm{PICO}=$ picophytoplankton $P^{(3)}$; SLOW = large slow-growing phytoplankton $P^{(4)}$.

\section{Discussion}

Despite the limitation of direct model-data comparisons by means of compilations of sparse biological data, it has been shown that the processes implemented in the model can explain a reasonable portion of the biogeochemistry of the system. Particularly, the agreement of the oxygen simulation confirms the model skills in reproducing the seasonality of the production periods and the overall biological variability in the long term.

Nevertheless, some mechanisms related to nutrient recycling in the BSW and the fate of the organic matter in the BIW need further investigation. Notwithstanding the uncertainties on the role of the external nutrient sources which are discussed in the last section, the results shown above indicate an excess of $\mathrm{P}$ with respect to $\mathrm{N}$ in the surface layer (Fig. 8a) and an accumulation of inorganic nutrients above the pycnocline in the summer period (Figs. 7, 8 and 9b). The former occurs in spite of the high $\mathrm{N}: \mathrm{P}$ ratio in the river input, implying that $\mathrm{N}$ is removed faster than $\mathrm{P}$ in the modelled BSW. Data indicate a more intense summer production which would require the availability of additional sources of N. However, these sources can only be partially traced from concentration measurements, especially whether they are from diffusion across the thermocline, local regeneration in the euphotic zone or bacterial N-fixation. Distinct summer blooms of cyanobacteria are observed in the Bornholm basin (HELCOM, 1996) and measurements in the eastern Gotland basin have revealed that $\mathrm{N}_{2}$ fixation can account up to twice the spring bloom $\mathrm{N}$ uptake (Schneider et al., 2003).

On the other hand, the nutrient accumulation predicted by the model in the BIW apparently has no direct effect on the winter pool of nutrients because the breaking of the thermo- 
(a) Phosphate (Surface)

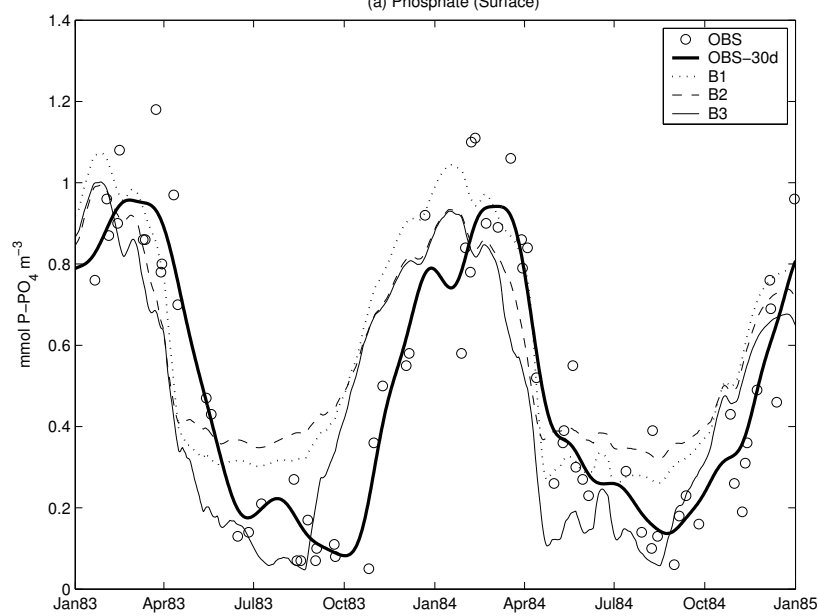

(b) Ammonium (Surface)

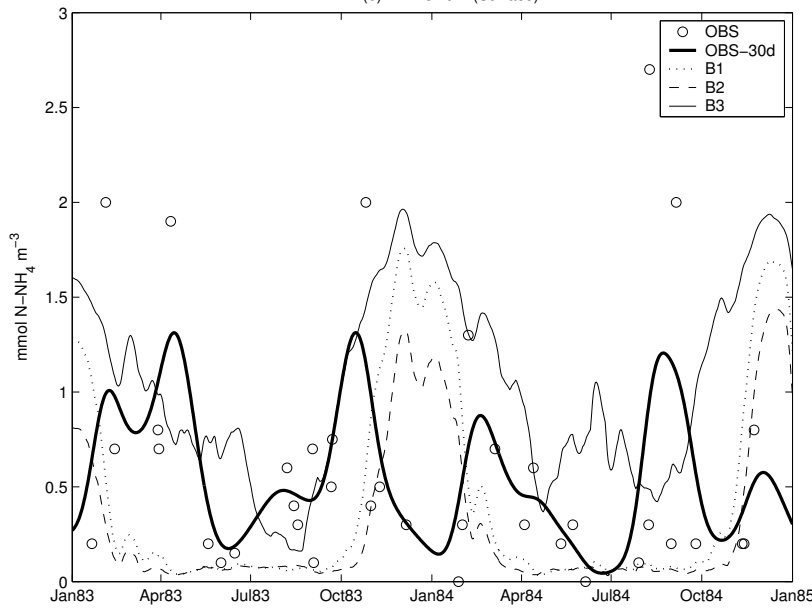

Fig. 12. Comparison of the observed phosphate (a) and ammonium (b) concentrations at the surface with the results of the processoriented simulations for the period 1983-1984. Model results are filtered with a $15 \mathrm{~d}$ running mean and observational data are interpolated with a $30 \mathrm{~d}$ Gaussian filter to underline the time evolution.

cline restores the observed concentration (Fig. 7b), but might have implications for the developments next spring due to the autumn production phase. Thomas et al. (2003a) have suggested that the BIW acts as a buffer for N, contributing to the winter maxima with this additional source. The suggested mechanism, derived from the analysis of $\mathrm{NO}_{3}$ profiles in the Baltic Proper, implies that the entrapped $\mathrm{N}$ is both a residual after the spring bloom and/or a mineralisation product of the organic matter produced in spring (Thomas et al., 1999).

Model results indicated mineralisation in the BIW to be the major mechanism causing N-enrichment, even if the predicted rates apparently are too high. At the same time, a too slow recycling is probably occurring in the modelled BSW, or the model lacks an additional source of $\mathrm{N}$ which might be due to diazotrophs. Both processes are not clearly supported by the observations and the question arises whether the model is overestimating nutrient mineralisation in the BIW or the data have an insufficient time resolution to reveal the underlying nutrient dynamics. The answer to these questions implies a review of our understanding of the (re)cycling times of organic matter in the different physical layers. The initial phases of the spring bloom and the nutrient drawdown are satisfactorily modelled, but this model (as most of the deterministic ecosystem models) has substantial approximations in parameterising the subtle processes that link the fate of organic matter to the local biogeochemical transformations in a post-bloom condition. In fact, organic matter can be locally recycled withinin the microbial loop eventually sustaining further primary production, or particulate organic matter can sink to the benthic pools, thus introducing a further time lag in the re-supply of mineralisation products.

The quantity and the nutrient: $\mathrm{C}$ ratios of particulate organic matter (POM) produced and exported during the postbloom conditions are therefore crucial for the mechanistic understanding of the nutrient dynamics in the surface and intermediate layers. The fast sinking of freshly-produced material is a possible way to reduce the residence time of $\mathrm{POM}$ in the BIW and thus the remineralisation rates. The sinking of C-rich and N-poor organic matter could also explain both high oxygen utilisation and lower mineralisation/accumulation rates of $\mathrm{N}$ in the BIW. This kind of material is typically excreted by nutrient-limited phytoplankton in the form of polysaccharides. The model is currently capable to simulate the production of nutrient-impoverished DOM (Vichi et al., 2003), but lacks the explicit production of polysaccharides. Recently, it has been proposed that particle formation by assemblage of dissolved organic macromolecules can be an efficient vehicle for converting existing DOC into POC (Engel et al., 2004). This might be a possible additional mechanism that would export $\mathrm{N}$-poor organic matter to the intermediate layers. Prior to the inclusion of such a feature, it is important to check what are the impacts of different sinking rates of POM and the production of polysaccharides on the nutrient dynamics of the model compared with the available observations.

\section{Process-oriented experiments}

The following process-oriented simulations were performed by modifying the structure of the model as detailed in the Appendix. The changes involved the introduction of a fastsinking detritus component and a reformulation of the parameterisations for phytoplankton and bacteria in order to explicitely include the excretion of polysaccharides and their utilisation within the microbial loop. The latter reparameterisation was derived from a specific model application to a set of mesocosm experiments (Ruardij et al., 2004) ${ }^{1}$. The results

\footnotetext{
${ }^{1}$ Ruardij, P., Veldhuis, M., and Brussaard, C.: Modelling bloom dynamics of the polymorphic phytoplankter Phaeocystis globosa: impact of grazers and virus, Harmful Algae, submitted, 2004.
} 
Table 1. Summary of the process-oriented experiments and scenario experiments.

\begin{tabular}{|c|c|c|c|c|}
\hline \multirow[t]{2}{*}{ Exp. } & \multirow[t]{2}{*}{ Description } & \multicolumn{3}{|c|}{ External inputs } \\
\hline & & Atmosphere (N) & River (N, P, Si, inorganic) & River $(\mathrm{C}, \mathrm{N}, \mathrm{P}$, organic $)$ \\
\hline B1 & Standard ERSEM III & yes & no & yes \\
\hline B2 & as $\mathrm{B} 1+$ fast-sinking detritus & yes & no & yes \\
\hline B3 & as B2 + polysaccharide dynamics & yes & no & yes \\
\hline B3-S1 & as $\mathrm{B} 3$ & yes & yes $^{1}$ & yes \\
\hline B3-S2 & as B3 & no & no & no \\
\hline B3-S3 & as B3 & yes & yes & yes \\
\hline
\end{tabular}

${ }^{1}$ Converted to organic form, assuming Redfield ratio for the C-component.

of these additional simulations were then compared with the reference run presented in the previous section (see Table 1 for the names and a summary of the experiments discussed herein).

The rationale for the addition of another detritus variable is the following. The spring bloom is dominated mainly by diatoms and this should enhance that part of the marine food web composed of large zooplankters leading to high sedimentation rates (Hagström et al., 2001). The standard ERSEM assumes that particulate detritus sinks with an average velocity of $1.5 \mathrm{~m} \mathrm{~d}^{-1}$, disregarding the origin of the detritus itself. However, faecal pellets have a high sinking velocity due to their density being much higher than the average one of organic substrate. Therefore, in run B2, it is prescribed that all mesozooplankton egestion is directed to this new component $\left(R_{i}^{(8)}\right.$ in Fig. 2) which has a faster sinking rate $\left(5 \mathrm{~m} \mathrm{~d}^{-1}\right)$ and is not available as substrate for bacterioplankton in the pelagic environment.

The parameterisation used in run B3, instead, has the same fast-sinking detritus but also includes two other fractions of the dissolved organic matter complex (DOM), polysaccharides and less-degradable carbohydrates $\left(R_{c}^{(2)}\right.$ and $R_{c}^{(7)}$ in Fig. 2, respectively). Sugars are now excreted when phytoplankton cannot equilibrate fixed $\mathrm{C}$ with sufficient nutrients to maintain the minimum quotum for the survival of the cells. This mechanism is different from the previous parameterisation (Baretta-Bekker et al., 1997; Vichi, 2002) where cell lysis was increased when phytoplankton had low nutrient:carbon ratios, which led not only to an extra release of C-enriched DOM but also to a decrease of the population biomass. In addition, the dynamics of bacteria, which already were improved with respect to ERSEM II by including the explicit dynamics of DOM (Vichi et al., 2003), was further modified to include the uptake of sugars and the release of less-degradable carbohydrates (see Appendix).

It is expected that these parameterisations on the one hand enhance the mineralisation processes in the BSW leading to an increase of summer phytoplankton biomass, and on the other hand, reduce the residence time of detritus in the BIW slowing down the recycling time.

\subsection{Surface layers}

Figure 12 illustrates the model trajectories compared with the surface data for phosphate and ammonium for the period 1983-1984. Runs B1 and B2 are quite similar, indicating that the faster removal of detritus from the surface does not have particular effects on the nutrient concentrations. This is particularly true for $\mathrm{PO}_{4}$, while the ammonium winter replenishment is reduced in run B2. The modified parameterisation of phytoplankton and bacteria brings the simulated phosphate much closer to the observations. This is due to the much larger presence of ammonium (Fig. 12b) that is used to increase the early-summer phytoplankton biomass and thus reducing the excess of $\mathrm{PO}_{4}$. It is interesting to notice the timeshift between the model prediction and the smoothed envelope of the observations. The depletion of nutrients is earlier by about one month in the model and the same occurs for the autumn-winter replenishment, hinting at the need to refine the light utilisation processes that mostly control the starting of the bloom. Additional sensitivity experiments have shown that it is not sufficient just to adjust the minimum optimal light for phytoplankton growth (cf. Ebenhöh et al., 1997, for details on the optimal light parameterisations), because it also has implications in the development of the autumn bloom that is considerably reduced. It is rather the lightacclimation mechanism that needs to be refined, therefore it is expected that the planned inclusion of explicit Chl synthesis will improve the results.

The description of the ammonium dynamics is rather complicated. It is striking how much $\mathrm{N}$ can be made available in the surface layer by assuming a different formulation of the phytoplankton internal dynamics. The data show a sort of bimodal dynamics through the year with a rather puzzling absence of a winter maximum. The first peak is found in February-April and the second one in August-October. The model generally overestimates the observations that are, however, rather sparse to give an indication of the real evolution. Moreover, the model considers as ammonium all the excretion products from micro- and mesozooplankton, which are mostly in the form of urea. Indeed, observations' inventories generally underestimate the bioavailability of $\mathrm{N}$ because 
(a) Oxygen Saturation (Intermediate)

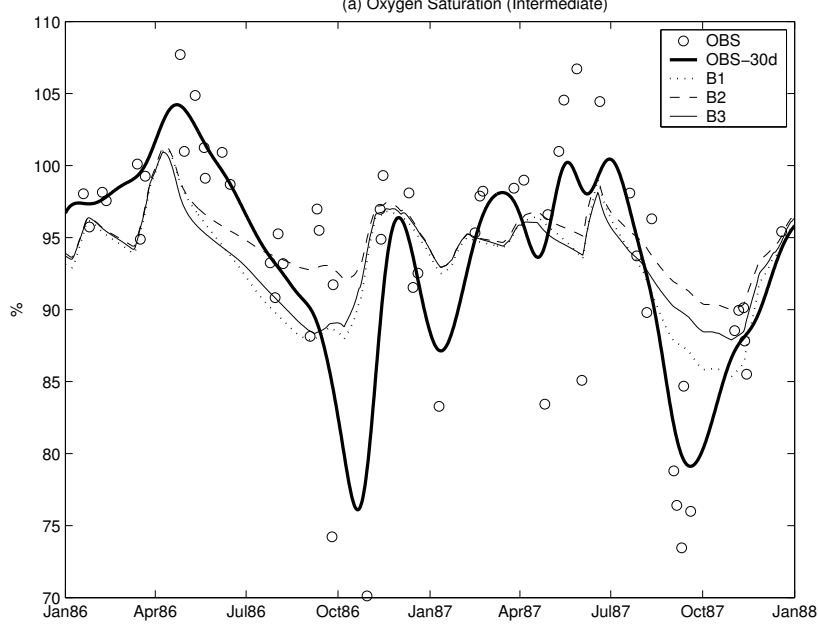

(b) Nitrate (Intermediate)

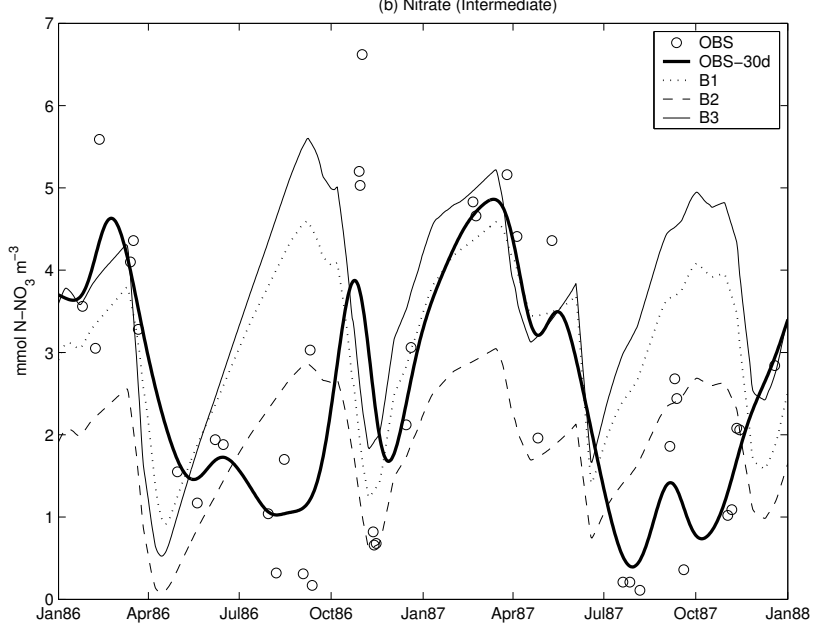

Fig. 13. Comparison of the observed nitrate concentration (a) and oxygen saturation (b) in the intermediate layer with the results of the process-oriented simulations for the period 1986-1987. Model results are filtered with a $15 \mathrm{~d}$ running mean and observational data are interpolated with a $30 \mathrm{~d}$ Gaussian filter to underline the time evolution.

this component is usually not included. Yet urea has been proven to be an important direct source of $\mathrm{N}$ for coastal phytoplankton in the northern Baltic (Tamminen and Irmisch, 1996), and it is likely that it is relevant also in the regenerated phase of plankton succession in the open sea.

\subsection{Intermediate layers}

Model behaviour in the BIW is not much improved by the extensions. The paradox of a lower oxygen consumption with an apparent absence of $\mathrm{N}$ mineralisation is still present both in runs B2 and B3, as shown for the period 1986-1987 in Fig. 13. The addition of fast-sinking detritus in run B2 further decreases the oxygen utilisation because more organic matter is exported to the bottom layers and the biological oxygen demand is reduced. Although this has the desired effect of reducing summer $\mathrm{NO}_{3}$ concentrations in the BIW, it also has as a consequence the diminishment of the winter supply (Fig. 13b), and hence of the spring phytoplankton biomass. The model gives indications that in a permanently stratified system like the Baltic Proper the differential sinking velocity of the organic particles may play a major role in determining the winter levels of nutrients. The process simulated here represents an upper limit of the recycling time-lag, because it was assumed that feacal pellets are not remineralised while sinking but only in the benthic system.

Run B3, which also includes fast-sinking detritus, is instead more comparable with B1. This is due to an unforeseen feedback between production and consumption phases in the different layers. Since one of the major aspects of the B3 parameterisation is to enhance the survival of phytoplankton cells at low nutrient concentrations, the surface layer has more biomass that reduces the light availability in this layer making it effectively less productive, reducing the oxygen to lower levels. This is a further indication that concentrations are not a good measure of the ongoing processes especially when several linked mechanisms participate in the overall time-evolution.

It is nevertheless likely that summer remineralisation of $\mathrm{N}$ (first ammonification and then nitrification) is a realistic process in the BIW. Figure 13b shows that considerable high concentrations of $\mathrm{NO}_{3}$ are observed prior to the breaking of the thermocline in middle October (this occurs several times in the time series but especially in 1986). The model, however, predicts that remineralisation starts when the stratification begins, which is clearly contrasted by the observed late-summer oxygen minima and nutrient maxima.

A possible solution of this discrepancy involves a scenario that was not possible to reproduce with the model. Bacteria have been shown to compete with phytoplankon for inorganic nutrients in the Baltic surface waters (Zweifel et al., 1993) and this is correctly simulated by the model in the summer period (not shown). In the BIW, bacteria are instead net remineralisers of nutrients because the organic substrate has sufficient $\mathrm{N}$ and $\mathrm{P}$ content to sustain the bacteria population. Modelled bacteria are therefore carbon-limited, which contrasts with the large amount of DOC found in the Baltic Proper (Hagström et al., 2001). Just a portion of this DOC is available to bacteria and the model assumes that this part is the more labile fraction produced during the spring-summer period. If bacteria were capable to degrade also a portion of the more refractory fraction, then they would also take up inorganic nutrients, increasing their respiration rate and delaying the remineralisation phase that then would be due mostly to heterotrophic flagellates. Additional measurements are therefore needed to assess the role of bacterioplankton in the BIW. 
Table 2. Mean annual net primary production (NPP), bacterial production (BP) and ratio between bacterial carbon demand (BCD) and gross primary production (GPP) in the water column.

\begin{tabular}{lccc}
\hline & $\begin{array}{c}\mathrm{NPP} \\
\left(\mathrm{g} \mathrm{C} \mathrm{m}^{-2} \mathrm{y}^{-1}\right)\end{array}$ & $\begin{array}{c}\text { BP } \\
\left(\mathrm{g} \mathrm{C} \mathrm{m}^{-2} \mathrm{y}^{-1}\right)\end{array}$ & $\begin{array}{c}\text { BCD:GPP } \\
(-)\end{array}$ \\
\hline B3 & 117 & 75 & 0.6 \\
B3-S1 & 133 & 75 & 0.6 \\
B3-S2 & 37 & 54 & 0.8 \\
B3-S3 & 169 & 75 & 0.6 \\
\hline
\end{tabular}

\section{External input scenarios}

In the Baltic scientific community there is a particular focus on the eutrophication effects and the role of the input of allochtonous nutrients (Elmgren, 2001). Recently, a nutrient load reduction experiment was performed with a threedimensional ecosystem model of the Baltic Sea composed of nine biological state variables (Neumann et al., 2002). This is an important step beyond 1-D models in order to have an appropriate description of all the hydrodynamical features and temporal developments that have to be parameterised in 1-D setups. However, a 3-D implementation is limited by computational requirements and generally requires the use of simplified biological processes especially for the benthic dynamics. Indeed, Neumann et al. (2002) found in the near bottom processes the largest discrepancies with the observations.

This section presents the response of the model to different scenarios of nutrient loads to the Baltic Proper. The 1-D setup allows to include more feedbacks between the biological variable and, particularly, the response of a fully-resolved benthic system. However, care must be taken in the interpretation of results because of the uncertainties related to the parameterisation of river inputs in a 1-D model (see Sect. 3.2).

The experiments are summarised in Table 1 and were performed with the B3 setup. The focus was on the effects of different ways to include the river nutrient loads described in Sect. 3.2, considering both organic and/or inorganic forms. Reference run B3 assumes that only the particulate organic fraction flux from rivers ( $\mathrm{C}, \mathrm{N}, \mathrm{P}$ components) is available in the model as degradable particulate detritus $\left(R_{i}^{(6)}, i=\right.$ $c, n, p$ in Fig. 2). This implies that all the inorganic river inputs are transformed in the vicinity of the sources and that no additional organic matter is exported to the open Baltic.

Case B3-S1 assumes that the inorganic river inputs are converted to organic particles in the coastal zone and exported to the model location. The $\mathrm{C}$ component associated to this organic matter flux is assumed to be in Redfield ratio with the $\mathrm{N}$ component. Experiment B3-S2 prescribes that no external nutrients, including atmospheric deposition, are available at the model location, and experiment B3-S3 assumes that all the nutrient inputs (both organic and inorganic, in their respective forms) from rivers and atmosphere reach the open Baltic Proper.

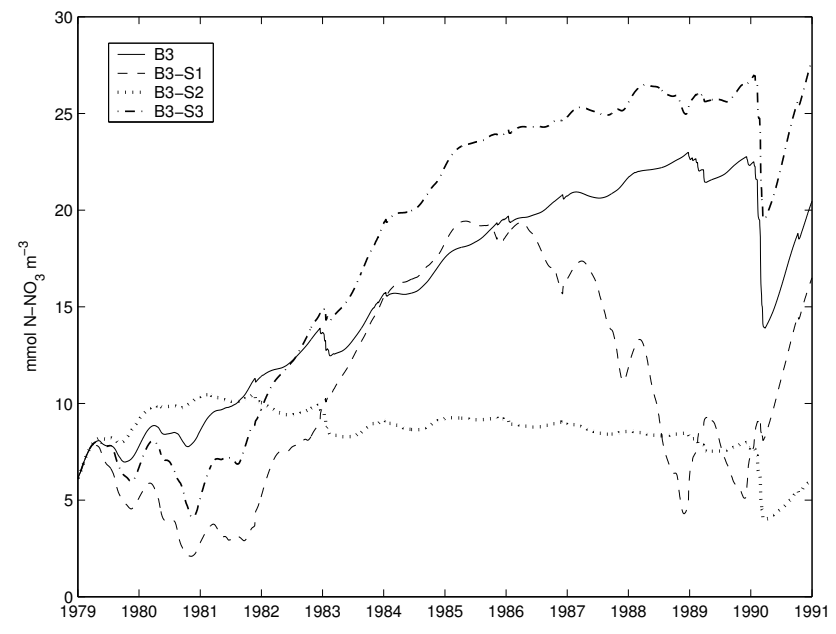

Fig. 14. Modelled nitrate concentration in the bottom layer for the scenario experiments listed in Table 1.

The discussion of model results is particularly focused on the nitrate dynamics and on the net ecosystem production, which can be both significantly affected by the stagnation conditions of the investigated period. Figure 14 shows how nitrate in the $\mathrm{BBW}$ is affected by the form of the external nutrient sources. The model predicts that, under identical physical conditions, nitrate accumulation in the BBW is a function of the quantity and composition of the external inputs as also speculated by Thomas et al. (2003a). High inorganic N inputs as in B3-S3 lead to a large increase of the bottom concentration. If large amounts of both organic nitrogen and carbon are simultaneously provided as in B3-S1, the system carrying capacity is exceeded and the organic matter is degraded in the benthic system leading to hypoxia and ultimately to denitrification. The absence of any external source as in B3$\mathrm{S} 2$, on the contrary, leads to a long-term equilibrium of the bottom concentration, which is continuously maintained by the winter mixing, the small supply of organic matter and by nitrification induced by the favourable oxic conditions.

Correspondingly, net primary production (NPP) increases as a function of the external nutrient availability irrespective of the quality of inputs as summarised in Table 2. The mean annual NPP integrated over the water column is maximum in the case of large inorganic river loads but also organic inputs alone can maintain elevated NPP. All the values are within the range reported by Hagström et al. (2001) for the Bornholm basin (132-256 $\left.\mathrm{g} \mathrm{C} \mathrm{m}^{-2} \mathrm{y}^{-1}\right)$. NPP is instead considerably lower in the idealised no-inputs case and the system is mostly sustained by bacterial production (BP). BP is constant in all the experiments with an external nutrient supply and the ratio between the bacterial carbon demand and the total fixed carbon is also constant, indicating that the metabolic response of bacterioplankton is probably more linked to the physical conditions and not to the autotrophic carbon. 


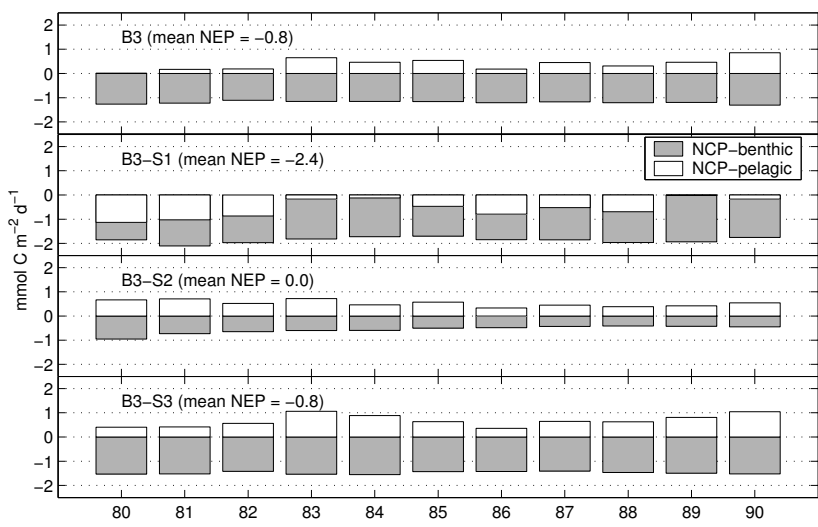

Fig. 15. Annual means of benthic and pelagic Net Community Production (NCP) for the scenario experiments in Table 1. The total Net Ecosystem Production (NEP) is the algebraic sum of the two time series and the average for each experiment is shown in brackets in the graphs.

However, Net Ecosystem Production (NEP, net primary production minus heterotrophic respiration) of a shallow basin is composed of the sum of pelagic and benthic metabolic processes, both considering the heterotrophic respiration terms. The time series of the average annual Net Community Productions (NCPs) over the 80 s are shown in Fig. 15 separated in the benthic and pelagic contributions. In run B3-S1, where the external inputs to the model domain are considered to be high and in organic form, the pelagic NCP is very low and always negative, as also reported in recent estimates by Gazeau et al. (2004). Pelagic NCP is maximum (or almost zero in B3-S1) in the period 1983-1985 when the nutrient supply from rivers is the highest. In spite of benthic heterotrophic respiration being low (only $5-8 \%$ of NPP is consumed there) this value is sufficient to change the total NEP to negative mean values (cf. bracketed values in Fig. 15). Only in the B3-S2 experiment there is a net balance between pelagic production and benthic consumption of organic carbon, indicating that without any additional source of nutrients the metabolic system state is adjusted towards a complete utilisation of the fixed carbon. In all the other experiments the average NEP is slightly negative (B3 and B3-S3) or even considerably negative in B3-S1, when all the inputs are already in organic form.

Given that the average inflow of organic carbon from external sources, which is assumed to have a Redfield ratio with the organic $\mathrm{N}$ fraction (cf. Sect. 3.2), is about $0.8 \mathrm{mmol} \mathrm{C}$ $\mathrm{m}^{-2} \mathrm{~d}^{-1}$, it turns out that the external input of organic matter regulates the behavior of the system towards being a sink for carbon. The input of inorganic nutrients as in B3-S3 is apparently not making the system more autotrophic, because the total average NEP is still equal to B3, indicating that all the additional new production is processed below the halocline and finally in the benthic system.

\section{Conclusions}

The one-dimensional watercolumn approach is sufficient to explain a large portion of the system variability observed in the open Baltic, particularly in the surface layers where the bulk of the organic matter production processes occur. The good agreement with the observed surface temperature indicates that the calculated heat and momentum fluxes are correct, and that the vertical mixing processes above the pycnocline are to some extent properly represented. Comparative analyses of modelled hydrochemical components with respect to the independent BED observations have shown that the long-term system behaviour of the model remains internally consistent and within "likely" boundaries. Oxygen saturation, used as a proxy for system net production/consumption, is also in good agreement with the observations. It is important to point out that oxygen dynamics are substantially affected by the computation of the gas transfer velocities at the air-sea interface (Liss and Merlivat, 1986). Additional sensitivity tests with a refined gastransfer parameterisation for the Baltic Sea proposed by Kuss et al. (2004) have shown that modelled winter oxygen concentrations agree better with the observations in all the layers. Particuarly, a cubic dependency of the wind forcing appears superior, but also enhances the discrepancy with the observations in summer, which are probably due to underestimated primary productivity by the model, as pointed out in Sect. 4.3.

Yet some discrepancies with the nutrient observations highlight the presence of unresolved mechanisms that limit the simulation of open Baltic biogeochemistry. Particularly, the model is not very good at hindcasting hydrochemical data in the Baltic intermediate waters (BIW). The modifications in the structure of the model with respect to previous formulations (cf. Sect. 7) have shown that the nutrient dynamics in the BIW are linked to the quality and size distribution of the organic matter produced in the euphotic zone and settling through this layer. This is a partial confirmation that the strategy of including more (although uncertain) interactions among the system components can increase the model skill in reproducing observations. Additional process-oriented experimental studies are needed to further clarify the effective bioavailability of the organic compounds, the transition from DOC to POC through aggregation mechanisms (Engel et al., 2004), and also the importance of light-acclimation of phytoplankton in these intermediate layers at the lower edge of the euphotic zone.

In summary, model results suggest that the Baltic Proper is a site where nutrient and carbon cycling are strongly uncoupled, and that there is an efficient preferential recycling of nutrients in the surface and intermediate layers, as also speculated by Thomas et al. (2003a). This recycling enhances both primary production as well as heterotrophic respiration, and the model indicates that most of the carbon produced in the euphotic zone is mostly oxidised below the permanent halo- 
cline and only a small fraction (less than $10 \%$, cf. Sect. 7) in the benthic system. These results are in agreement with the behaviour observed in the eastern Gotland basin during the stagnation period from 1995 to 1999 (Schneider et al., 2002). The authors estimated that about $85 \%$ of the organic carbon produced in the surface layers is mineralised in the intermediate layers and that only $15 \%$ reaches the sediment surface.

The explanation suggested by the model for this kind of behaviour lies in the physical structure of the Baltic Proper: the zone of net production is separated from the consumption zones by semi-permanent stratification as in the deep ocean, but because of the relatively shallow water column the two regions are tightly connected by the sinking process. This process removes potential local sources of regenerated nutrients causing $\mathrm{N}$-limitation in the surface layer but temporarily storing the organic matter in the BIW. Here the fate of the organic matter bifurcates: it is partly processed by the microbial foodweb, leading to local remineralisation, and partly sinks down to below the halocline. Both mechanisms lead to heterotrophic consumption of organic matter with different time scales, and the quality of the organic substrate is indicated by the model as a possible discriminant. Particularly, the size of the particulate organic matter formed during the bloom periods and the dynamics of polysaccharides in the post-bloom conditions have been shown to impact the nutrient evolution in the surface and intermediate layers. In the future, the addition of DOC aggregation processes as recently suggested by Engel et al. (2004) could help to solve some of the remaining discrepancies between model and observations.

The annual variability in the summer meteorological conditions can sometimes reduce the separation between the BSW and the BIW, effectively supplying recycled nutrients via turbulent diffusion and increasing net production as shown, for instance, in 1984 and 1987. Additional sources of $\mathrm{N}$, however, are needed in the surface layer to increase the summer primary production and to bring it closer to the observations. The model suggests that slow-growing phytoplankton $P^{(4)}$ is favoured under these stratified conditions. These features they share with the filamentous cyanobacteria found in the Baltic summer blooms (HELCOM, 1996), apart from the ability to fix atmospheric nitrogen, which is not implemented in the model. The simulated biomass of $P^{(4)}$ is lower in the period 1985-1988 as also reported for the filamentous cyanobacteria population in the Baltic Proper (Kahru, 1997; Neumann et al., 2002). Therefore model results support the idea that biological $\mathrm{N}$-fixers are a possible temporary contribution to the nitrogen supply in thermally stratified waters as also derived by Larsson et al. (2001) and Schneider et al. (2003) in the northern Baltic Proper by analysing changes in nitrate and $\mathrm{CO}_{2}$ concentrations.

The organic matter exported to below the pycnocline is then consumed in the deeper layers and in the benthic system, which in the investigated period are almost permanently sep- arated because of the persistent stagnation conditions. Given that NPP is within the observed range, the overall calculated biogeochemical fluxes describe a system that is net source of inorganic carbon. This metabolic response is a consequence of the external sources of nutrients, both in organic and inorganic form. A logical conclusion from the analysis of the model results is that the input of anthropogenic nutrients moves the system towards a more heterotrophic state. Particularly, the input of organic loads tends to exacerbate the heterotrophic conditions. In addition, the model suggests that, in a scenario without any allochtonous sources of nutrients, the open Baltic has a balanced $\mathrm{C}$ budget. With regard to $\mathrm{N}$ budgets, nitrogen accumulation is instead substantially affected by the quality of anthropogenic inputs. The supply of inorganic $\mathrm{N}$ increases the storage of nitrate in the bottom layers, while the input of organic $\mathrm{N}$ makes the picture much more complicated, shifting the system from $\mathrm{N}$ accumulation to denitrification depending on the annual variability of the stratification conditions.

It is likely that the different mechanisms and nutrient load scenarios that were analysed separately with the model, in reality occur in combination, depending on the hydrodynamical conditions. In fact, the coastal zone is a transitional area around the freshwater point sources that does modify the external fluxes which ultimately supply these open areas. The computation of NEP is thus hampered by the uncertainties in the quantity and quality of the horizontal export fluxes through the model domain that necessarily are neglected in the 1-D approximation. A 3-D model is undoubtedly superior in resolving these dynamics, although the results obtained here with a 1-D model are comparable with the 3-D simulations by Neumann et al. (2002) also in the physical evolution.

In particular, model results indicate that the inclusion of a fully-resolved benthic system can impact the time-evolution of nutrients and oxygen in the Baltic bottom waters. Although most of the POM is processed in the intermediate layers, the benthic fluxes of nutrient and oxygen at the sediment system can ultimately process the deposited organic matter, making the system definitely heterotrophic. It is thus likely that, as also pointed out by Schneider et al. (2002) in the deeper parts of the Baltic Proper, the benthic system can potentially mineralise most of the organic substrate produced in the coastal zone and transported with the deep currents. Therefore, direct simultaneous measurements of sedimentation rates of organic matter and sediment oxygen demand are needed to compare with and verify the results suggested by the model. 


\section{Appendix A}

\section{Model equations}

This Appendix describes the changes in the parameterisation of phytoplankton and bacteria. The biological source terms solved in the standard ERSEM phytoplankton are gross primary production (gpp), respiration (rsp), exudation (exu), cell lysis (lys) and predation (prd). As detailed in Vichi (2002), there is an equation for any internal component of a generic phytoplankton group, $P_{i}(z, t) \equiv\left(P_{c}, P_{n}, P_{p}, P_{s}\right)$. In each term, the subscript indicates the variable the flux is exchanged with. The list of variables is shown in Fig. 2 and the parameter values and their complete description is available as additional material (http://www.copernicus.org/EGU/ $\mathrm{bg} / \mathrm{bg} / 1 / 79 / \mathrm{bg}-1-79$-supp.pdf).

$$
\begin{aligned}
& \left.\frac{\partial P_{c}}{\partial t}\right|_{\text {bio }}=\left.\frac{\partial P_{c}}{\partial t}\right|_{O^{(3)}} ^{\mathrm{gpp}}-\left.\frac{\partial P_{c}}{\partial t}\right|_{R_{c}^{(i)}} ^{\mathrm{exu}}- \\
& \left.\frac{\partial P_{c}}{\partial t}\right|_{O^{(3)}} ^{\mathrm{rsp}}-\left.\frac{\partial P_{c}}{\partial t}\right|_{R_{c}^{(i)}} ^{\mathrm{lys}}-\left.\sum_{j} \frac{\partial P_{c}}{\partial t}\right|_{Z_{c}^{(j)}} ^{\mathrm{prd}} \\
& \left.\frac{\partial P_{n}}{\partial t}\right|_{\text {bio }}=\left.\frac{\partial P_{n}}{\partial t}\right|_{N^{(3)}, N^{(4)}} ^{\mathrm{upt}}-\left.\frac{\partial P_{n}}{\partial t}\right|_{R_{n}^{(i)}} ^{\mathrm{lys}}-\left.\frac{P_{n}}{P_{c}} \sum_{j} \frac{\partial P_{c}}{\partial t}\right|_{Z_{c}^{(j)}} ^{\mathrm{prd}} \\
& \left.\frac{\partial P_{p}}{\partial t}\right|_{\text {bio }}=\left.\frac{\partial P_{p}}{\partial t}\right|_{N^{(1)}} ^{\mathrm{upt}}-\left.\frac{\partial P_{p}}{\partial t}\right|_{R_{p}^{(i)}} ^{\mathrm{lys}}-\left.\frac{P_{p}}{P_{c}} \sum_{j} \frac{\partial P_{c}}{\partial t}\right|_{Z_{c}^{(j)}} ^{\mathrm{prd}} \\
& \left.\frac{\partial P_{s}}{\partial t}\right|_{\text {bio }}=\left.\frac{\partial P_{s}}{\partial t}\right|_{N^{(5)}} ^{\mathrm{upt}}-\left.\frac{\partial P_{s}}{\partial t}\right|_{R_{s}^{(6)}} ^{l y s}-\left.\frac{P_{s}}{P_{c}} \sum_{j} \frac{\partial P_{c}}{\partial t}\right|_{Z_{c}^{(j)}} ^{\mathrm{prd}} \\
& \text { if } P_{s}=P_{s}^{(1)}, \text { otherwise }\left.\frac{\partial P_{s}}{\partial t}\right|_{\mathrm{bio}}=0 .
\end{aligned}
$$

The equations for bacterioplankton are written in a similar manner, including the processes of bacterial carbon uptake (bcd) and the uptake or remineralisation of inorganic nutrients (upt/rel). Bacteria are assumed to have no release of organic matter, therefore their loss terms are limited to respiration and predation.

$$
\begin{aligned}
& \left.\frac{\partial B_{c}}{\partial t}\right|_{\text {bio }}=\left.\frac{\partial B_{c}}{\partial t}\right|_{R_{c}^{(i)}} ^{\mathrm{bcd}}-\left.\frac{\partial B_{c}}{\partial t}\right|_{O^{(3)}} ^{\mathrm{rsp}}-\left.\sum_{j} \frac{\partial B_{c}}{\partial t}\right|_{Z_{c}^{(j)}} ^{\mathrm{prd}}(5) \\
& \left.\frac{\partial B_{n}}{\partial t}\right|_{\text {bio }}=\left.\frac{R_{n}^{(i)}}{R_{c}^{(i)}} \frac{\partial B_{c}}{\partial t}\right|_{R_{c}^{(i)}} ^{\mathrm{bcd}}+\left.f_{B}^{n} \frac{\partial B_{n}}{\partial t}\right|_{N^{(k)}} ^{\mathrm{upt}, \mathrm{rel}}-\left.\frac{B_{n}}{B_{c}} \sum_{j} \frac{\partial B_{c}}{\partial t}\right|_{Z_{c}^{(j)}} ^{\mathrm{prd}}(6) \\
& \left.\frac{\partial B_{p}}{\partial t}\right|_{\text {bio }}=\left.\frac{R_{p}^{(i)}}{R_{c}^{(i)}} \frac{\partial B_{c}}{\partial t}\right|_{R_{p}^{(i)}} ^{\mathrm{bcd}}+\left.f_{B}^{p} \frac{\partial B_{p}}{\partial t}\right|_{N^{(1)}} ^{\text {upt,rel }}-\left.\frac{B_{p}}{B_{c}} \sum_{j} \frac{\partial B_{c}}{\partial t}\right|_{Z_{c}^{(j)}} ^{\mathrm{prd}}(7)
\end{aligned}
$$

All the predation terms in the above equations are written similarly with a Holling type II formulation, taking into account the different prey-predator availability (Broekhuizen et al., 1995; Vichi, 2002).

\section{Experiment B1: standard ERSEM III}

Gross primary production is a function of the environmental conditions and of the external silicate concentration in the case of diatoms $P^{(1)}$.

$$
\left.\frac{\partial P_{c}}{\partial t}\right|_{O^{(3)}} ^{\mathrm{gpp}}=Q_{10}^{\frac{T-10}{10}} \min \left(1, I_{\mathrm{PAR}} / I_{P}^{\mathrm{opt}}\right)\left(\frac{N^{(5)}}{N^{(5)}+h_{P^{(1)}}^{s}}\right) r_{0_{P}} P_{c},(8)
$$

where $T$ is the modelled water temperature, $I_{P A R}$ is the Photosynthetically Available Radiation (attenuated by the suspended particles) and $I_{P}^{\mathrm{opt}}$ the optimal light computed according to Ebenhöh et al. (1997). The activity exudation term

$$
\left.\frac{\partial P_{c}}{\partial t}\right|_{R_{c}^{(1)}} ^{\text {exu }}=\left.\left[\alpha_{P}+\left(1-\alpha_{P}\right)\left(1-f_{P}^{n, p}\right)\right] \frac{\partial P_{c}}{\partial t}\right|_{O^{(3)}} ^{\mathrm{gpp}}
$$

is controlled by the internal nutrient ratios according to the following Liebig-like regulating factor (always constrained between 0 and 1 ):

$$
f_{P}^{n, p}=\min \left(\frac{P_{n} / P_{c}-n_{P}^{\min }}{R r^{n}-n_{P}^{\min }}, \frac{P_{p} / P_{c}-p_{P}^{\min }}{R r^{p}-p_{P}^{\min }}\right) .
$$

Respiration is divided in metabolic and activity as:

$$
\left.\frac{\partial P_{c}}{\partial t}\right|_{O^{(3)}} ^{\mathrm{rsp}}=Q_{10}^{\frac{T-10}{10}} b_{P} P_{c}+\gamma_{P}\left\{\left.\frac{\partial P_{c}}{\partial t}\right|_{O^{(3)}} ^{g p p}-\left.\frac{\partial P_{c}}{\partial t}\right|_{R_{c}^{(1)}} ^{e x u}\right\}
$$

The lysis products are a function of the total nutrient stress factor $f_{P}^{p, n, s}=\min \left(f_{P}^{n, p}, \frac{N^{(5)}}{N^{(5)}+h_{P(1)}^{s}}\right)$, and are partitioned into particulate and dissolved detritus according to a dynamical fraction $\varepsilon_{P}^{n, p}=\min \left(1, \frac{p_{P}^{\min }}{P_{p} / P_{c}}, \frac{n_{P}^{\min }}{P_{n} / P_{c}}\right)$ :

$$
\begin{aligned}
\left.\frac{\partial P_{c}}{\partial t}\right|_{R_{c}^{(6)}} ^{\mathrm{lys}} & =\varepsilon_{P}^{n, p} \frac{h_{P}^{p, n, s}}{f_{P}^{p, n, s}+h_{P}^{p, n, s}} d_{0_{P}} P_{c} ; \\
\left.\frac{\partial P_{c}}{\partial t}\right|_{R_{c}^{(1)}} ^{\mathrm{lys}} & =\left(1-\varepsilon_{P}^{n, p}\right) \frac{h_{P}^{p, n, s}}{f_{P}^{p, n, s}+h_{P}^{p, n, s}} d_{0_{P}} P_{c} .
\end{aligned}
$$

The uptake of nutrients is regulated by a Droop kinetic as detailed in Baretta-Bekker et al. (1997) and Vichi (2002):

$$
\begin{aligned}
& \left.\frac{\partial P_{n}}{\partial t}\right|_{N^{(3)}, N^{(4)}} ^{\text {upt }}= \\
& \min \left(\lambda_{3}^{\text {ext }} N^{(3)} P_{c}+\lambda_{4}^{\text {ext }} N^{(4)} P_{c}, G_{P} n_{P}^{\max }+v_{P}\left(n_{P}^{\max }-\frac{P_{n}}{P_{c}}\right) P_{c}\right)
\end{aligned}
$$

$$
\begin{aligned}
& \left.\frac{\partial P_{p}}{\partial t}\right|_{N_{p}^{(1)}} ^{u p t}= \\
& \min \left(\lambda_{1}^{e x t} N^{(1)} P_{c}, G_{P} p_{P}^{\max }+v_{P}\left(p_{P}^{\max }-\frac{P_{p}}{P_{c}}\right) P_{c}\right),
\end{aligned}
$$


where $G_{P}$ is the net growth, the algebraic sum of the first 4 terms on the right hand side of Eq. (1). If the $\mathrm{N}$ uptake rate (13) is positive, then the partitioning between $N^{(3)}$ and $N^{(4)}$ uptake is done using the ratios $\frac{\lambda_{3}^{\text {ext }} N^{(3)}}{\lambda_{3}^{\text {ext }} N^{(3)}+\lambda_{4}^{\lambda^{e x t}} N^{(4)}}$ and $\frac{\lambda_{4}^{\text {ext }} N^{(4)}}{\lambda_{3}^{\text {ext }} N^{(3)}+\lambda_{4}^{\text {ext }} N^{(4)}}$, respectively. If it is negative, as in the case of dark respiration when there may be an excess of intracellular nutrients, the whole flux is directed to the ammonium pool $N^{(4)}$

The lysis process affects phytoplankton nutrient content exactly proportionally to the total carbon loss in (12) with the exception that the particulate fraction has always the minimum $\mathrm{N}: \mathrm{C}$ or $\mathrm{P}: \mathrm{C}$ ratios. For phosphorus it is written as:

$$
\begin{aligned}
& \left.\frac{\partial P_{p}}{\partial t}\right|_{R_{p}^{(6)}} ^{\mathrm{lys}}=\left.p_{P}^{\min } \frac{\partial P_{c}}{\partial t}\right|_{R_{c}^{(1)}, R_{c}^{(6)}} ^{\mathrm{lys}} \\
& \left.\frac{\partial P_{p}}{\partial t}\right|_{R_{p}^{(1)}} ^{\mathrm{lys}}=\left.\left(\frac{P_{p}}{P_{c}}-p_{P}^{\min }\right) \frac{\partial P_{p}}{\partial t}\right|_{R_{c}^{(1)}, R_{c}^{(6)}} ^{\mathrm{lys}} .
\end{aligned}
$$

For the silicate dynamics (4) there is no internal storage (but only structural) and silicate is released only in particulate form proportionally to the carbon lysis:

$$
\left.\frac{\partial P_{s}^{(1)}}{\partial t}\right|_{N^{(5)}} ^{\text {upt }}=G_{P} S_{P^{(1)}}^{\max } P_{c}^{(1)} ;\left.\frac{\partial P_{s}^{(1)}}{\partial t}\right|_{R_{s}^{(6)}} ^{\text {lys }}=\left.\frac{P_{s}}{P_{c}} \frac{\partial P_{p}}{\partial t}\right|_{R_{c}^{(1)}, R_{c}^{(6)}} ^{\text {lys }}
$$

Bacterioplankton formulation has been also described in Vichi et al. (2003). The following equations are reported for comparison with the new parameterisations proposed in Sect. 8 .

$$
\begin{aligned}
& \left.\frac{\partial B_{c}}{\partial t}\right|_{R_{c}^{(1)}, R_{c}^{(6)}} ^{\mathrm{bcd}}= \\
& \min \left(f_{B}^{n, p} Q_{10}^{\frac{T-10}{10}} r_{0_{B}} B_{c}, v_{R^{(6)}} f_{R^{(6)}}^{n, p} R_{c}^{(6)}+v_{R^{(1)}} f_{R^{(1)}}^{n, p} R_{c}^{(1)}\right),
\end{aligned}
$$

where the regulating factors (constrained between 0 to 1 ) for the bacterial potential growth and the substrate uptake are, respectively:

$$
\begin{aligned}
& f_{B}^{n, p}=\min \left(\frac{B_{p} / B_{c}}{p^{o p t}}, \frac{B_{n} / B_{c}}{n^{o p t}}\right) ; \\
& f_{R^{(j)}}^{n, p}=\min \left(\frac{R_{p}^{(j)} / R_{c}^{(j)}}{p^{o p t}}, \frac{R_{p}^{(j)} / R_{c}^{(j)}}{n^{o p t}}\right) j=1,6 .
\end{aligned}
$$

Respiration accounts for basal and activity respiration, taking into account the metabolic costs at low oxygen concentrations:

$$
\begin{aligned}
& \left.\frac{\partial B_{c}}{\partial t}\right|_{O^{(3)}} ^{\mathrm{rsp}}= \\
& b_{B} Q_{10}^{\frac{T-10}{10}} B_{c}+\left.\left[1-\eta_{B}-\eta_{B}^{o}\left(1-\frac{\left(O^{(2)}\right)^{3}}{\left(O^{(2)}\right)^{3}+\left(h_{B}^{o}\right)^{3}}\right)\right] \frac{\partial B_{c}}{\partial t}\right|_{R_{c}^{(1)}, R_{c}^{(6)}} ^{\mathrm{bcd}}(19)
\end{aligned}
$$

Depending on the internal nutrient-to-carbon ratios, bacteria can behave as remineralisers or as competitors with phytoplankton, taking up inorganic nutrients directly from the water.

$$
\begin{aligned}
& \left.\frac{\partial B_{p}}{\partial t}\right|_{N^{(1)}} ^{\text {upt,rel }}=f_{B}^{p} v_{B}^{p}\left(\frac{B_{p}}{B_{c}}-p_{B}^{\max }\right) B_{c} \\
& \left.\frac{\partial B_{n}}{\partial t}\right|_{N^{(4)}} ^{\text {upt,rel }}=f_{B}^{n} v_{B}^{n}\left(\frac{B_{n}}{B_{c}}-n_{B}^{\max }\right) B_{c} .
\end{aligned}
$$

For phosphorus, if $\frac{B_{p}}{B_{c}}-p_{B}^{\max }>0$ (excretion of nutrients) the non-dimensional parameter $f_{B}^{p}$ gets values -1 , and if $\frac{B_{p}}{B_{c}}-p_{B}^{\max }<0$ there is direct uptake from the water as a function of the nutrient concentration in a Michaelis-Menten form $\frac{N^{(1)}}{N^{(1)}+h_{B}^{p}}$.

Experiment B2: parameterisation of fast sinking detritus

The equations are the standard ERSEM III ones with the addition of a new variable $R_{i}^{(8)}$ with $\mathrm{C}, \mathrm{N}, \mathrm{P}$ components $(i=c, n, p)$. The egestion from mesozooplankton, instead of being released as labile detritus $R_{i}^{(6)}$ is directed to $R_{i}^{(8)}$. The carbon equation for mesozooplankton comprises an ingestion term, an egestion/mortality term and a respiration term. The following is the formulation of the egestion mortality flux:

$$
\begin{aligned}
& \left.\frac{\partial Z_{c}}{\partial t}\right|_{R_{c}^{(8)}} ^{\text {out }}= \\
& \alpha_{Z} Q_{10}^{\frac{T-10}{10}} r_{0_{Z}} \frac{\sum_{X} \delta_{Z, X} X_{c}}{\sum_{X} \delta_{Z, X} X_{c}+\frac{r_{Z}}{v_{Z}}} Z_{c}+d_{0_{Z}} Q_{10}^{\frac{T-10}{10}} Z_{c}+d_{Z}^{\mathrm{dns}} Z_{c}^{\beta},
\end{aligned}
$$

where the first term on the RHS is the released portion of the ingestion rate and the other terms are mortality rates due to senescense and density effects. Parameter $\delta_{Z, X}$ represents the availability of prey $X$ to predator $Z$ (food matrix element). The release fluxes of the nutrient components of $R^{(8)}$ are computed from the carbon fluxes by means of the fixed internal ratios of mesozooplankton.

Experiment B3: polysaccharide excretion

Phytoplankton gross growth is not modified from Eq. (8). The exudation and lysis terms are instead much simplified because the stress lysis has been replaced by exudation of polysaccharides $R_{c}^{(2)}$. Sugars are also the products of the activity exudation and lysis is just considered as a first order mortality term mostly due to viral attacks:

$$
\left.\frac{\partial P_{c}}{\partial t}\right|_{R_{c}^{(2)}} ^{\mathrm{exu}}=\left.\alpha_{P} \frac{\partial P_{c}}{\partial t}\right|_{O^{(3)}} ^{\mathrm{gpp}} ;\left.\frac{\partial P_{c}}{\partial t}\right|_{R_{c}^{(1)}, R_{c}^{(6)}} ^{\mathrm{lys}}=d_{0_{P}} P_{c} .
$$

The respiration term is thus rewritten as:

$$
\left.\frac{\partial P_{c}}{\partial t}\right|_{O^{(3)}} ^{\mathrm{rsp}}=Q_{10}^{\frac{T-10}{10}} b_{P} P_{c}+\left.\gamma_{P}\left(1-\alpha_{P}\right) \frac{\partial P_{c}}{\partial t}\right|_{O^{(3)}} ^{\mathrm{gpp}} .
$$


One of the major features of this formulation is that it does not assume any Redfield-like optimal ratio between cellular carbon and nutrients as in Eq. (10). The carbon exudation is computed after the calculation of the nutrient uptake, which is written as in Eq. (14) for phosphate but has been slightly modified for nitrogen taking into account the inhibition of $N^{(3)}$ uptake in presence of $N^{(4)}$ :

$$
\begin{aligned}
& \left.\frac{\partial P_{n}}{\partial t}\right|_{N^{(3)}, N^{(4)}} ^{u p t}= \\
& \min \left(\lambda_{2}\left(\frac{h_{P}^{n}}{h_{P}^{n}+N^{(4)}} N^{(3)}+N^{(4)}\right) P_{c}, G_{P} n_{P}^{\max }+v_{P}\left(n_{P}^{\max }-\frac{P_{n}}{P_{c}}\right) P_{c}\right) .
\end{aligned}
$$

The total exudation of sugars is composed of the activity release (Eq. 23) and the release flux of fixed carbon that has not been incorporated into biomass due to nutrient limitations:

$$
\begin{aligned}
& \left.\frac{\partial P_{c}}{\partial t}\right|_{R_{c}^{(2)}} ^{\text {exu }}= \\
& \left.\alpha_{P} \frac{\partial P_{c}}{\partial t}\right|_{O^{(3)}} ^{g p p}+\min \left(0, G_{P},\left.\frac{1}{n_{P}^{\min }} \frac{\partial P_{n}}{\partial t}\right|_{N^{(3)}, N^{(4)}} ^{\text {upt }},\left.\frac{1}{p_{P}^{\min }} \frac{\partial P_{p}}{\partial t}\right|_{N_{p}^{(1)}} ^{\text {upt }}\right) .
\end{aligned}
$$

Bacterioplankton equations have been modified to incorporate the uptake of sugars. The quality of the substrate, i.e. the ratios between nutrient and carbon in DOM, is not used to control the availability for bacterial uptake by means of the quality factors (Eq. 18) as in Eq. (27). Bacterial carbon demand is now parameterised as

$$
\begin{aligned}
& \left.\frac{\partial B_{c}}{\partial t}\right|_{R_{c}^{(1)}, R_{C}^{(2)} R_{c}^{(6)}} ^{b c d}= \\
& \min \left(f_{B}^{n, p} Q_{10}^{\frac{T-10}{10}} r_{0_{B}} B_{c}, \sum_{j=1,2,6} v_{R^{(j)}} R_{c}^{(j)}\right) .
\end{aligned}
$$

Nutrient uptake is different from Eqs. (20) and (21) making it much similar to phytoplankton. If the specific uptake rate of $\mathrm{N}$ from substrate is larger that the minimum rate sufficient to sustain the bacterial production, then bacteria are net remineralisers of ammonium:

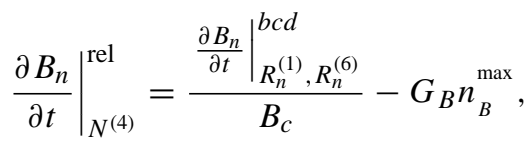

where $G_{B}$ is net bacterial production, the difference between Eq. (27) and the respiration (Eq. 19) which is not modified from the original formulation. If the nutrient uptake from substrate is insufficient, bacteria take up inorganic nutrients, and just like phytoplankton, bacteria have access to nitrate as in Eq. (25):

$$
\begin{aligned}
& \left.\frac{\partial B_{n}}{\partial t}\right|_{N^{(3)}, N^{(4)}} ^{\text {upt }}= \\
& \min \left(-\lambda_{B}^{2}\left(\frac{h_{B}^{n}}{h_{B}^{n}+N^{(4)}} N^{(3)}+N^{(4)}\right), \frac{\left.\frac{\partial B_{n}}{\partial t}\right|_{R_{n}^{(1)}, R_{n}^{(6)}} ^{\mathrm{bcd}}-G_{B} n_{B}{ }^{\max }}{B_{c}}\right)
\end{aligned}
$$

In Eqs. (28) and (29), the uptake of nutrients related to the carbon uptake is computed as

$$
\left.\frac{\partial B_{n}}{\partial t}\right|_{R_{n}^{(1)}, R_{n}^{(6)}} ^{\mathrm{bcd}}=\left.\sum_{j=1,6} \frac{R_{n}^{(j)}}{R_{c}^{(j)}} \frac{\partial B_{c}}{\partial t}\right|_{R_{c}^{(j)}} ^{\mathrm{bcd}} .
$$

Bacteria finally release the excess of carbon as refractory carbohydrates $R_{c}^{(7)}$ in order to equilibrate their internal ratios. This flux exists only if the nutrient ratios in the net uptake of substrate is above the minimum ratio for the survival of the cell:

$$
\begin{aligned}
& \left.\frac{\partial B_{c}}{\partial t}\right|_{R_{c}^{(7)}} ^{\text {out }}= \\
& G_{B}-\min \left(G_{B}, \frac{\left.\frac{\partial B_{p}}{\partial t}\right|_{R_{p}^{(1)}, R_{p}^{(6)}} ^{b c d}}{p_{B}^{\min }}, \frac{\left.\frac{\partial B_{n}}{\partial t}\right|_{R_{n}^{(1)}, R_{n}^{(6)}} ^{\text {bcd }}}{n_{B}^{\min }}\right) .
\end{aligned}
$$

Acknowledgements. This study was initiated in the framework of the European Project BASYS (MAS3-CT96-0058) at the Danish Hydraulic Institute (DHI Water \& Environment). The authors ackowledge the data availabilty from the project and particularly from the Baltic Environmental Database at the Stockholm University. MV wishes to thank W. Ebenhöh and the staff at the Oldenburg University, N. Pinardi and A. Navarra for their support. MV was supported by a Marie Curie Research Training Grant (MAS3-CT97-5050) and by the Italian Ministry for Environment and Territory.

Edited by: S. W. A. Naqvi

\section{References}

Axell, L.: On the variability of Baltic Sea deep-water mixing, J. Geophys. Res., 103, 21 667-21 682, 1998.

Baretta, J., Ebenhöh, W., and Ruardij, P.: The European Regional Seas Ecosystem Model, a complex marine ecosystem model, J. Sea Res., 33, 233-246, 1995.

Baretta-Bekker, J., Baretta, J., and Ebenhoeh, W.: Microbial dynamics in the marine ecosystem model ERSEM II with decoupled carbon assimilation and nutrient uptake, J. Sea Res., 38, 195-212, 1997.

Blackford, J.: An analysis of benthic biological dynamics in a North Sea ecosystem model, J. Sea Res., 38, 213-230, 1997.

Blumberg, A. and Mellor, G.: A description of a three-dimensional coastal ocean circulation model, in Three-dimensional coastal ocean model, edited by Heaps, N., American Geophysical Union, 1-16, 1987.

Broekhuizen, N., Heath, M., Hay, S., and Gurney, W.: Modelling the dynamics of the North Sea's mesozooplankton, J. Sea Res., 33, 381-406, 1995.

Castellari, S., Pinardi, N., and Leaman, K.: A model study of air-sea interactions in the Mediterranean Sea, J. Mar. Sys., 18, 89-114, 1998.

Dobson, F. and Smith, S.: Bulk model of solar radiation at the sea, Q. J. R. Meteorol. Soc., 114, 165-182, 1988. 
Ebenhöh, W., Kohlmeier, K., and Radford, P.: The benthic biological submodel in the European Regional Seas Ecosystem Model, J. Sea Res., 33, 423-452, 1995.

Ebenhöh, W., Baretta-Bekker, J., and Baretta, J.: The primary production module in the marine ecosystem model ERSEM II with emphasis on the light forcing, J. Sea Res., 38, 173-193, 1997.

Eilola, K. and Stigebrandt, A.: On the seasonal nitrogen dynamics of the Baltic proper biogeochemical reactor, J. Mar. Res., 57, 693-713, 1999.

Elmgren, R.: Understanding human impact on the Baltic ecosystem: changing views in recent decades, Ambio, 30, 222-231, 2001.

Engel, A., Thoms, S., Riebesell, U., Rochelle-Newall, E., and Zondervan, I.: Polysaccharide aggregation as a potential sink of marine dissolved organic carbon, Nature, 428, 929-932, 2004.

Fonselius, S.: Oxygen and hydrogen sulphide conditions in the Baltic Sea, Mar. Poll. Bull., 12, 187-194, 1981.

Gattuso, J.-P., Frankignoulle, M., and Wollast, R.: Carbon and carbonate metabolism in coastal aquatic ecosystems, Annu. Rev. Ecol. Syst., 29, 405-433, doi:10.1146/annurev.ecolsys.29.1.405, 1998.

Gazeau, F., Smith, S., Gentili, B., Frankignoulle, M., and Gattuso, J.-P.: The European coastal zone: characterization and first assessment of ecosystem metabolism, Estuar. Coast. Shelf S., 60, 673-694, 2004.

Geider, R., MacIntyre, H., and Kana, T.: A dynamic regulatory model of phytoplanktonic acclimation to light, nutrients, and temperature, Limnol. Oceanogr., 43, 679-694, 1998.

Hagström, Å., Azam, F., Kuparinen, J., and Zweifel., U.: Pelagic plankton growth and resource limitations in the Baltic Sea, in A System Analysis of the Baltic Sea, edited by Wulff, F., Rahm, L., and Larsson, P., Ecological Studies, 148, 7, 177-210, SpringerVerlag, Berlin Heidelberg, 2001.

HELCOM: First periodic assessment of the state of the marine environment of the Baltic Sea, 1980-1985, Balt. Sea Environ. Proc. 17 B, Helsinki Commission, Helsinki, 1987.

HELCOM: Second periodic assessment of the state of the marine environment of the Baltic Sea, 1984-1988; Background document, Balt. Sea Environ. Proc. 35 B, Helsinki Commission, Helsinki, 1990.

HELCOM: Third periodic assessment of the state of the marine environment of the Baltic Sea, 1989-1993; Background document, Balt. Sea Environ. Proc. 64 B, Helsinki Commission, Helsinki, 1996.

Herbert, R.: Nitrogen cycling in coastal marine ecosystems, FEMS Microb. Rev., 23, 563-590, 1999.

Kahru, M.: Using satelites to monitor large-scale environmental changes: a case study of cyanobacterial blooms in the Baltic Sea, in Monitoring algal blooms: new techniques for detecting large-scale environmental changes, Springer-Verlag, Heidelberg Berlin, 43-61, 1997.

Kuss, J., Nagel, K., and Schneider, B.: Evidence from the Baltic Sea for an enhanced $\mathrm{CO}_{2}$ air-sea transfer velocity, Tellus $\mathrm{B}, 56$, 175-175, 2004

Larsson, U., Hajdu, S., Walve, J., and Elmgren, R.: Baltic Sea nitrogen fixation estimated from the summer increase in upper mixed layer total nitrogen, Limnol. Oceanogr., 46, 811-820, 2001.

Lehmann, A. and Hinrichsen, H.-H.: On the thermohaline variability of the Baltic Sea, J. Mar. Sys., 25, 333-357, 2000.
Liss, P. and Merlivat, L.: Air-sea gas exchange rates: introduction and synthesis, in The role of air-sea exchange in Geochemical cycling, edited by Buat-Menard, P., 113-127, 1986.

Mellor, G. and Yamada, T.: Development of a Turbulence Closure Model for Geophysical Fluid Problems, Rev. Geophys. Space Phys., 20, 851-875, 1982.

Neumann, T., Fennel, W., and Kremp, C.: Experimental simulations with an ecosystem model of the Baltic Sea: a nutrient load reduction experiment, Glob. Biogeochem. Cy., 16, 1033, doi:10.1029/2001GB001450, 2002.

Nommann, S. and Kaasik, E.: Hydrodynamical control of phytoplankton succession during the vernal light-limited phase in the Baltic Sea, Mar. Ecol. Prog. Ser., 84, 279-291, 1992.

Omstedt, A. and Axell, L. B.: Modeling the seasonal, interannual, and long-term variations of salinity and temperature in the Baltic proper, Tellus, 50A, 637-652, 1998.

Rahm, L., Jönsson, A., and Wulff, F.: Nitrogen fixation in the Baltic proper: an empirical study, J. Mar. Sys., 25, 239-248, 2000.

Rönner, U. and Sörensson, F.: Denitrification rates in the lowoxygen waters of the stratified Baltic proper, Appl. Environ. Microbiol., 50, 801-806, 1985.

Ruardij, P. and Van Raaphorst, W.: Benthic nutrient regeneration in the ERSEM ecosystem model of the North Sea, J. Sea Res., 33, 453-483, 1995.

Schneider, B., Nausch, G., Kubsch, H., and Petersohn, I.: Accumulation of total $\mathrm{CO}_{2}$ during stagnation in the Baltic Sea deep water and its relationship to nutrient and oxygen concentrations, Mar. Chem., 77, 277-291, 2002.

Schneider, B., Nausch, G., Nagel, K., and Wasmund, N.: The surface water $\mathrm{CO}_{2}$ budget for the Baltic Proper: a new way to determine nitrogen fixation, J. Mar. Sys., 42, 53-64, 2003.

Smith, S. and Hollibaugh, J.: Coastal metabolism and the oceanic organic carbon balance, Rev. Geophys., 31, 75-90, 1993.

Sokolov, A. and Wulff, F.: SwingStations: a web-based client tool for the Baltic Environmental Database, Comp. Geosci., 25, 863$871,1999$.

Stigebrandt, A.: A model for the vertical circulation of the Baltic deep water, J. Phys. Oceanogr., 17, 1772-1785, 1987.

Stockenberg, A. and Johnstone, R.: Benthic denitrification in the Gulf of Bothnia, Estuar. Coast. Shelf S., 45, 835-843, 1997.

Stålnacke, P., Grimvall, A., Sundblad, K., and Tonderski, A.: Estimation of riverine loads of nitrogen and phosphorus to the Baltic Sea, 1970-1993, Environ. Monit. Assess., 58, 173-200, 1998.

Tamminen, T. and Irmisch, A.: Urea uptake kinetics of a midsummer planktonic community on the SW coast of Finland, Mar. Ecol. Prog. Ser., 130, 201-211, 1996.

Thomas, H., Ittekkot, V., Osterroht, C., and Schneider, B.: Preferential recycling of nutrients - the ocean's way to increase new production and to pass nutrient limitation?, Limnol. Oceanogr., 44, 1999-2004, 1999.

Thomas, H., Pempkowiak, J., Wulff, F., and Nagel, K.: Autotrophy, nitrogen accumulation and nitrogen limitation in the Baltic Sea: a paradox or a buffer for eutrophication?, Geophys. Res. Lett., 30, 2130, doi:10.1029/2003GL017937, 2003a.

Thomas, H., Pempkowiak, J., Wulff, F., and Nagel, K.: Carbon and nutrient budgets of the Baltic Sea, in Carbon and nutrient fluxes in continental margins: A global synthesis, edited by Liu, K. Atkinson, L., Quinones, R., and Talue-McManus, L., SpringerVerlag, in press, 2003b. 
Tsunogai, S., Watanabe, S., and Sato, T.: Is there a "continental shelf pump" for the absorption of atmospheric $\mathrm{CO}_{2}$ ?, Tellus, 51B, 701-712, 1999.

Tuominen, L., Heinanen, A., Kuparinen, J., and Nielsen, L.: Spatial and temporal variability of denitrification in the sediments of the northern Baltic proper, Mar. Ecol. Prog. Ser., 172, 13-24, 1998.

Vichi, M.: Predictability studies of coastal marine ecosystem behavior, Ph.D. thesis, University of Oldenburg, Oldenburg, Germany, http://docserver.bis.uni-oldenburg.de/publikationen/ dissertation/2002/vicpre02/vicpre02.html, 2002.

Vichi, M., Oddo, P., Zavatarelli, M., Coluccelli, A., Coppini, G., Celio, M., Fonda Umani, S., and Pinardi, N.: Calibration and validation of a one-dimensional complex marine biogeochemical fluxes model in different areas of the northern Adriatic shelf., Ann. Geophysicae, 21, 413-436, 2003,

SRef-ID: 1432-0576/ag/2003-21-413.
Wanninkhof, R.: Relationship between windspeed and gas exchange over the ocean, J. Geophys. Res., 97, 7373-7382, 1992.

Wulff, F. and Rahm, L.: A database and its tools., in Large-scale environmental effects and ecological processes in th Baltic Sea. Research program for the period 1990-1995 and background documents., edited by Wulff, F., 3856, 13, 217-225, SNV Report, Stockholm, Sweden, 1990.

Wulff, F. and Stigebrandt, A.: A time-dependent budget model for nutrients in the Baltic Sea, Glob. Biogeochem. Cy., 3, 63-78, 1989.

Zweifel, U., Norrman, B., and Å. Hagström: Consumption of dissolved organic carbon by marine bacteria and demand for inorganic nutrients, Mar. Ecol. Prog. Ser., 101, 23-32, 1993. 